\title{
molecules
}

ISSN 1420-3049

www.mdpi.com/journal/molecules

Review

\section{Cannabinoids: New Promising Agents in the Treatment of Neurological Diseases}

\section{Sabrina Giacoppo ${ }^{1}$, Giuseppe Mandolino ${ }^{2}$, Maria Galuppo ${ }^{1}$, Placido Bramanti ${ }^{1}$ and Emanuela Mazzon ${ }^{1, *}$}

1 IRCCS Centro Neurolesi “Bonino-Pulejo”, Via Provinciale Palermo, contrada Casazza, 98124 Messina, Italy

2 Consiglio per la Ricerca e la sperimentazione in Agricoltura, Centro di Ricerca per le Colture Industriali (CRA-CIN), Via di Corticella 133, 40128 Bologna, Italy

* Author to whom correspondence should be addressed; E-Mail: emazzon.irccs@gmail.com; Tel.: +39-090-6012-8708; Fax: +39-090-6012-8850.

External Editor: Derek J. McPhee

Received: 6 October 2014; in revised form: 7 November 2014 / Accepted: 7 November 2014 / Published: 17 November 2014

Abstract: Nowadays, Cannabis sativa is considered the most extensively used narcotic. Nevertheless, this fame obscures its traditional employ in native medicine of South Africa, South America, Turkey, Egypt and in many regions of Asia as a therapeutic drug. In fact, the use of compounds containing Cannabis and their introduction in clinical practice is still controversial and strongly limited by unavoidable psychotropic effects. So, overcoming these adverse effects represents the main open question on the utilization of cannabinoids as new drugs for treatment of several pathologies. To date, therapeutic use of cannabinoid extracts is prescribed in patients with glaucoma, in the control of chemotherapy-related vomiting and nausea, for appetite stimulation in patients with anorexia-cachexia syndrome by HIV, and for the treatment of multiple sclerosis symptoms. Recently, researcher efforts are aimed to employ the therapeutic potentials of Cannabis sativa in the modulation of cannabinoid receptor activity within the central nervous system, particularly for the treatment of neurodegenerative diseases, as well as psychiatric and non-psychiatric disorders. This review evaluates the most recent available data on cannabinoids utilization in experimental and clinical studies, and highlights their beneficial effects in the prevention of the main neurological diseases and for the clinical treatment of symptoms with them correlated. 
Keywords: Cannabis sativa; cannabinoids; cannabinoid receptors; neurodegenerative diseases; epilepsy

\section{Introduction}

Cannabis is probably one of the most ancient non-food crops cultivated by mankind; it belongs to the botanical family of Cannabaceae, along with Humulus, the cultivated hop. It is an annual, dioecious plant, though monoecious varieties have been bred, and its diploid chromosomic complement is $2 n=20$, with 18 autosomes and a couple of sexual chromosomes (XY for male and XX for female and monoecious plants [1].

The Cannabis species originated from Central Asia, where it was probably domesticated over 6000 years ago, but it has since been cultivated at virtually all latitudes for a large number of end-products deriving from the seed (e.g., fatty acids and proteins), the fiber, the wooden core and from the inflorescences, where cannabinoids are produced and secreted [2]. There still is limited agreement on whether Cannabis sativa should be considered a single species or a poly-species genus; however, the species boundaries, if existing, are weak, as full intercrossing between the different Cannabis accessions can occur, and several molecular markers-based analyses confirmed that Cannabis is a highly heterozygous species, with the intra-accession variation as wide as the inter-accession one [3].

In recent years, the debate on Cannabis re-introduction in our agricultural landscapes went beyond the agronomical and productive virtues of the plant, and especially focused on the potential of the plant's main metabolites, the cannabinoids, as medicines useful for a number of therapeutical applications [4].

In fact, medications based on Cannabis have been used for therapeutic purposes in many cultures for centuries [5], with descriptions of its effects including alterations in mood, cognitive functions, memory and perception of the user [6].

In Europe, they were used at the end of the 19th century to alleviate a wide variety of conditions, including pain, spasms, dysentery, depression, sleep disturbance and loss of appetite [7]. In the first half of the 20th century cannabinoid medications fell into almost complete disuse, partly because scientists were unable to establish the chemical structure of the ingredients of the Cannabis plant (Cannabis sativa L.).

It was only in 1964 that the psychoactive component of the Cannabis resin and flowers, $\Delta^{9}$-tetrahydrocannabinol $\left(\Delta^{9}\right.$-THC) was isolated [8]. Following, numerous non-psychoactive cannabinoids have been identified, such as cannabidiol (CBD), cannabigerol (CBG), cannabichromene (CBC), $\Delta^{9}$-tetrahydrocannabivarin $\left(\Delta^{9}\right.$-THCV) and cannabidivarin (CBDV). These compounds exert multiple actions through mechanisms that are only partially related to modulation of the endocannabinoid system.

In recent years, a growing interest has been dedicated to the study of cannabinoids for their antioxidant, anti-inflammatory and neuroprotective effects $[9,10]$. Specifically, $\Delta^{9}$-THC is the most widely studied phytocannabinoid, but also the predominant psychotropic component of Cannabis, strongly limiting its therapeutic use as an isolated agent. Therefore, recently research focused to include non-psychotropic compounds, some of which exhibit potential as therapeutic agents in preclinical models of central nervous system (CNS) disease. 
The present review focused on the current state of evidence regarding the possible usefulness of cannabinoid agents (psychotropic and non-psychotropic) in prevention of the main neurological disorders and/or in the treatment of symptoms correlated to them, at least in association with existing conventional therapy.

\section{Current Cannabinoid-Based Drugs}

Despite the illegality of Cannabis in most nations, a renewed interest in its medicinal properties has led to development of a number of cannabinoid-based medicines. Currently three drugs are used in clinical practice.

Dronabinol (Marinol ${ }^{\circledR}$, Solvay Pharmaceuticals, Brussels, Belgium) capsules, a synthetic formulation of $\Delta^{9}$-THC, was approved by the U.S. Food and Drug Administration in 1986, for the management of nausea and vomiting associated with cancer chemotherapy in patients who have not responded to conventional antiemetic treatments [11]. Dronabinol is also used for the treatment of anorexia with weight loss in patients with HIV/AIDS [12].

Nabilone (Cesamet ${ }^{\circledR}$, Valeant Pharmaceuticals International Inc, Mississauga, ON, Canada) capsules, is another synthetic derivative of $\Delta^{9}$-THC that is similar to dronabinol, but appears to be more potent. It was first approved in Canada in 1982 and is now also available in the United States and United Kingdom, still for the treatment of emesis [13].

Unlike Dronabinol and Nabilone, Sativex ${ }^{\circledR}$ (GW Pharma, Ltd, Salisbury, Wiltshire, UK) is administered in an oral spray, consisting of a mixture of two extracts in approximately a 1:1 ratio $\left(2.7 \mathrm{mg}\right.$ of $\Delta^{9}$-THC and $2.5 \mathrm{mg}$ of CBD) in an alcoholic solution (50\% ethanol). In Spain, Germany, Denmark as well as in Canada, United Kingdom and Italy, Sativex ${ }^{\circledR}$ is used as treatment to alleviate spasticity in adult multiple sclerosis (MS) patients which did not show an appropriate response to other drugs during an initial trial period of therapy $[14,15]$. Compared to the oral route, its advantage is a faster plateau of plasma concentration. Also, it has been established that coadministration of CBD and $\Delta^{9}$-THC can reduce unwanted effects of $\Delta^{9}$-THC.

\section{Synthesis and Production of Phytocannabinoids}

Although Cannabis plant can be defined as a true "chemical factory" extremely rich in secondary compounds, therapeutic applications essentially rely on the cannabinoids. According to a recent review [16], there are almost 500 different chemical compounds synthesized by the Cannabis plant, and about 70 among these are cannabinoids. Cannabinoids are secondary compounds unique to the genus Cannabis, and therefore of taxonomic significance; they are terpenophenols, produced by the enzymatic condensation of a terpenic moiety (geranyl diphosphate) with a phenolic one (mainly olivetolic or divarinic acid).

There are two chemical characteristics of the cannabinoid molecule that are particularly relevant (Figure 1). The first is the carboxylic group on the phenolic ring of the cannabinoid; this group is readily lost upon drying or mild heating, leaving the decarboxylated form of the different cannabinoids. It is this decarboxylation that converts the native $\Delta^{9}$-tetrahydrocannabinolic acid (THCA) into $\Delta^{9}$-THC, the cannabinoid well known for its intoxicating and psychotropic effects. All cannabinoids in Cannabis plants are synthesized and accumulated in their acidic form [17]. 
Figure 1. (A) Structure of the most common cannabinoids found in Cannabis plants. All the compounds have been represented in their acidic, native form, and with a pentylic side chain; (B) the non-enzymatic decarboxylation of $\Delta^{9}$-tetrahydrocannabinolic acid (THCA) to THC.

A<smiles>CCCCCc1cc(O)c(CC=C(C)CCC=C(C)C)c(O)c1C(=O)O</smiles><smiles>CCCCCc1cc2c(c(O)c1C(=O)O)C1C=C(C)CCC1C(C)(C)O2</smiles><smiles>C=C(C)C1CCC(C)=CC1c1c(O)cc(CCCCC)c(C(=O)O)c1O</smiles>

Cannabigerolic acid (CBGA)

$\Delta^{9}$-Tetrahydrocannabinolic acid (THCA)

Cannabidiolic acid (CBDA)<smiles>CCCCCc1cc2c(c(O)c1C(=O)O)C=CC(C)(CCC=C(C)C)O2</smiles><smiles>C=C(C)C1CCC(O)C(C)C1c1c(O)cc(CCCCC)c(C(=O)O)c1C</smiles>

Cannabichromenic acid (CBCA)

Cannabielsoinic acid<smiles>CCCCCc1cc2c(c(O)c1C(=O)O)-c1ccccc1C(C)(C)O2</smiles>

Cannabinolic acid

B<smiles>CCCCCCCc1cc2c(c(O)c1C(=O)O)C1C=C(C)CCC1C(C)(C)O2</smiles>

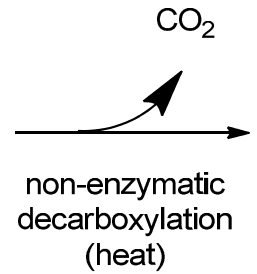

THCA

THC

The second relevant characteristic of the cannabinoid molecule is the polyketide chain present in meta position to the hydroxylic group of phenolic portion (Figure 1). The most abundant cannabinoids in Cannabis have in this position a pentyl chain, but also propyl and even methyl side chain groups have been described [18,19].

Cannabis sativa accessions and varieties have been divided into chemotypes, according to the main cannabinoid they produce at maturity and to their content ratio. Five chemotypes can be recognized as most commonly occurring: chemotype I has a very low cannabidiolic acid (CBDA)/THCA content ratio, and is mainly the chemotype found in drug strains. Chemotype III, on the contrary, is characterized by a very high CBDA/THCA ratio, and is typical of all cultivated fiber varieties. Chemotype II is a mixed chemotype, containing roughly equal amounts of CBDA and THCA, as can be found in hashish strains, but also in some old fiber varieties. Chemotype IV accumulates cannabigerolic acid (CBGA) as the main cannabinoid. Finally, plants showing no cannabinoids upon gas-chromatographic analysis of mature inflorescences have been described, and for these plants the chemotype $\mathrm{V}$ has been proposed [20]. Clearly, plants belonging to the different chemotypes have different potentials as sources for the active principles they synthesize, and the breeding of Cannabis for pharmaceutical purposes had as its first 
target the exploration and exploitation of the variability available in Cannabis germplasm for cannabinoid synthesis.

The sites of biosynthesis and accumulation of cannabinoids are the glandular trichomes (Figure 2A,B). Glandular trichomes are particularly dense in inflorescences, especially on the bracts, but also the leaves and, to a minor extent, the stems of Cannabis plants carry trichomes. Roots and seeds are devoid of any trichome, and, accordingly, these organs contain no cannabinoids. Glandular trichomes can be capitate-stalked, capitate-sessile, or bulbous, and these different morphologies are associated with a different quantity of cannabinoids accumulated [21].

Figure 2. Capitate-sessile (A) and bulbous (B) glandular trichomes. In (A), also some non-glandular trichomes (not secerning) are visible. (C), schematic representation of the current model of secretion of cannabinoids from the trichomes.
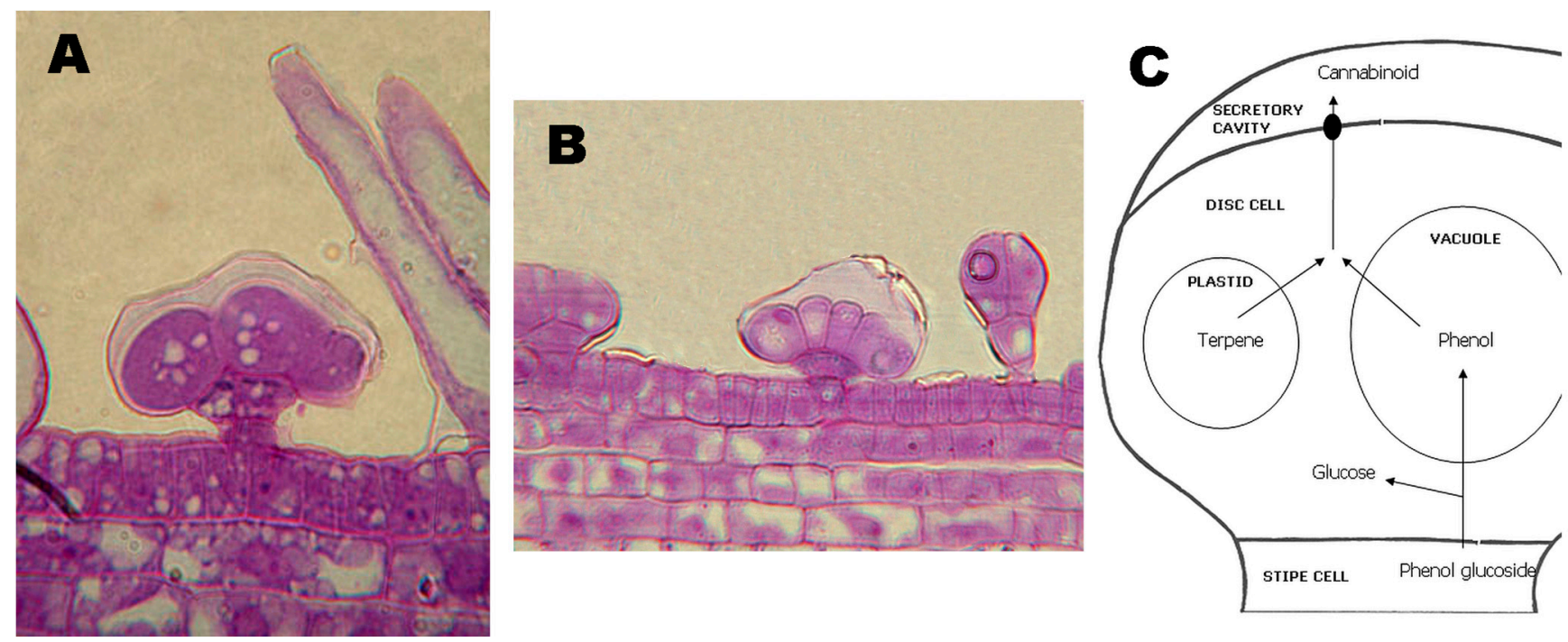

The glandular trichomes density is a trait especially important when breeding Cannabis for pharmaceutical purposes. In nature, the meaning for the plant's fitness of the accumulation of cannabinoids in trichomes is still debated; it has been proposed that the conjugate bonds system characterizing THCA might have helped to protect plant functions from UV, a hypothesis partially supported by the origin of high-THCA Cannabis strains in regions with a high UV irradiance.

The first committed step in the biosynthesis of cannabinoids is the prenylation of terpene geranyl diphosphate with olivetolic acid (or, less frequently, divarinic acid), to yield the cannabinoid considered today to be the precursor of all other cannabinoids, the CBGA (Figure 3). This enzymatic step is catalyzed by the enzyme geranylpyrophosphate: olivetolate geranyltransferase (GOT). The length of the side chain (determined by the preferential use of olivetolic or divarinic acid as the phenolic component of the cannabinoid) is a genetically determined trait, though specific genes involved have not yet been identified [22]. From the pharmaceutical point of view, this "variations on the theme" due to the different length of the alkylic side chain has a great potential, as it is likely that each member of the alkyl-homologs series for each cannabinoid could be endowed with different and specific therapeutical properties [23]. 
Figure 3. The biosynthesis of the main cannabinoids.

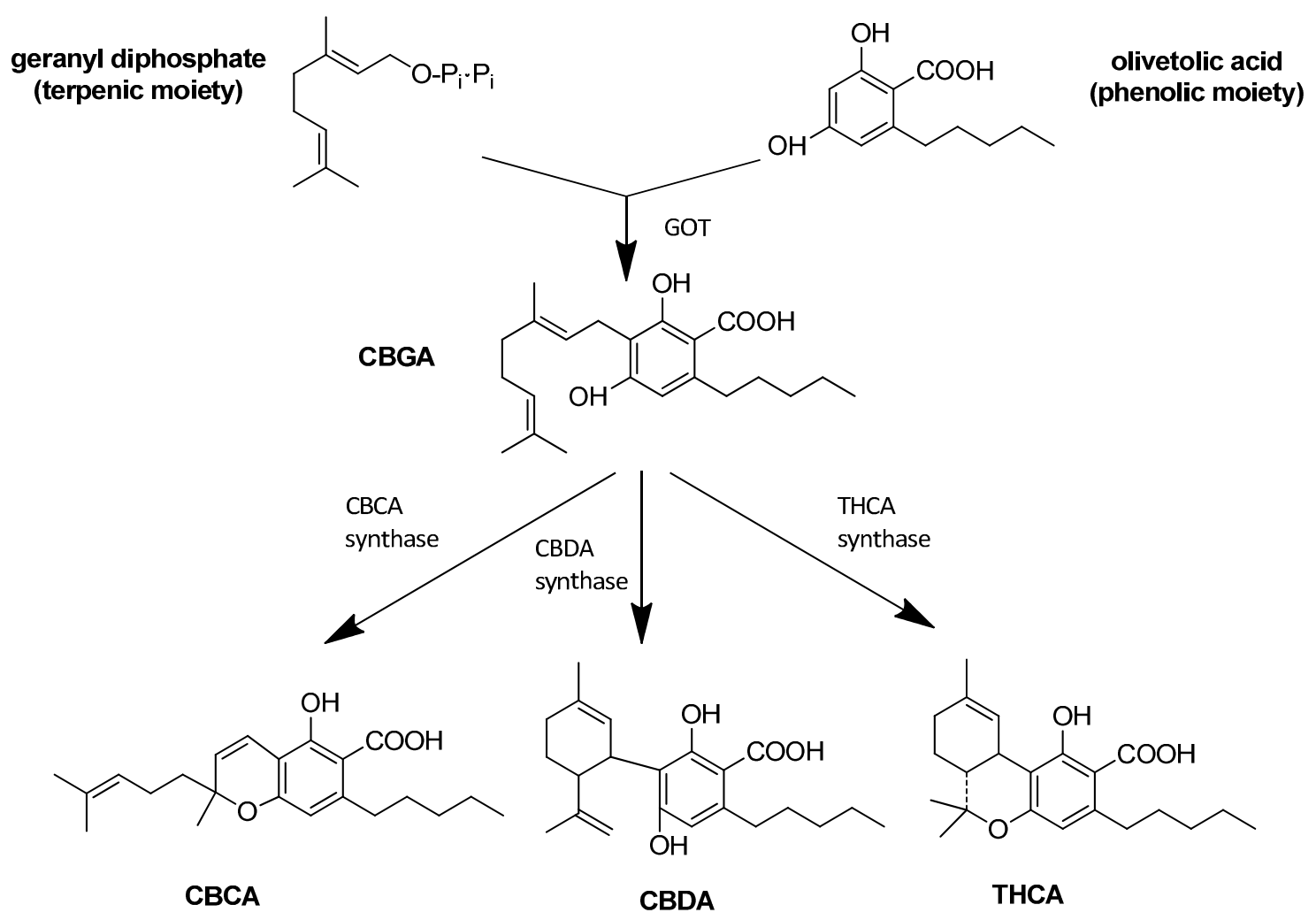

CBGA is the precursor of the most abundant cannabinoids deriving from enzymatic transformation, i.e., THCA, CBDA and cannabichromenic acid (CBCA). These three cannabinoids are synthesized through the oxidocyclization of CBGA mediated by three specific enzymes, THCA-synthase (THCAs), CBDA-synthase (CBDAs) and CBCA-synthase (CBCAs) (Figure 3). These enzymes have been isolated from inflorescences of different Cannabis strains or growth stages, and biochemically characterized in detail [24].

The hypothesis that the THCAs and CBDAs genes were alleles at the same locus, and that therefore the two proteins were isoenzymes, found confirmation by in-depth genetic analysis. The cross of pure-THCA breeding lines with pure-CBDA ones systematically yields F1 progenies producing equal amounts of both cannabinoids; besides, upon selfing or intercrossing of F1 plants, the F2 offspring obtained showed a perfect 1:2:1 segregation of pure-THC: mixed THC+CBD: pure CBD chemotypes [19], as expected for a single locus (termed $B$ ) with two codominant alleles, $B_{\mathrm{T}}$ and $B_{\mathrm{D}}$, respectively, coding for THCAS and CBDAS. These data confirmed that, despite the several environmental factors able to modulate the total amount of cannabinoids, the chemotype (i.e., the THCA/CBDA content ratio) has a simple Mendelian inheritance, while the amount of cannabinoids produced by the plant is a typically quantitative trait. The two aspects of inheritance of cannabinoids had a great impact on breeding of Cannabis, mainly for pharmaceutical purposes.

Nowadays, the increased availability of sequence data for several Cannabis sativa strains related to genes encoding for the biosynthesis of secondary compounds of therapeutic interest has led to the development of advanced tools for breeding and selection of therapeutic Cannabis varieties. For their use in modern pharmaceutical industry, these varieties are highly uniform, and devoted to the production of a specific single cannabinoid, or of a specific blend of different cannabinoids; even the zero-cannabinoid 
varieties have been used in clinical tests as placebo. The completion of the sequencing of the Cannabis genome and the extensive characterization of the alleles encoding for different cannabinoid synthase variants, promises to further widen the portfolio of phytocannabinoids available for therapeutic applications; besides, the recent definition of the tertiary structure of THCAS by X-ray crystallography at the $2.75 \AA$ resolution, with the identification of specific aminoacids crucial for enzyme function, pave the way for several biotechnological applications for synthesis of the cannabinoids ex planta [25].

\section{Cannabinoid Receptors}

In the human body there are specific binding sites for cannabinoids, distributed on the surface of many different cells. To date, two types of receptors have been identified to have different tissue distribution and mechanisms of signaling.

$\mathrm{CB} 1$ receptors, of which $\mathrm{CB}_{1 \mathrm{~A}}$ and $\mathrm{CB}_{1 \mathrm{~B}}$ represent two subtypes [26,27], are localized in the CNS [28]. Particularly, in the brain CB1 receptors are mainly expressed in areas involved in motor coordination and movement (cerebellum, basal ganglia and substantia nigra), attention and complex cognitive functions (cerebral cortex), learning, memory and emotions (amygdala and hippocampus) [29,30].In addition, CB1 receptors are present to a lesser extent in some organs and peripheral tissues, including endocrine glands, leukocytes, spleen, heart and part of the reproductive, urinary and gastrointestinal systems [31].

$\mathrm{CB} 1$ receptors reduce neuronal cell activity and interfere with the release of some neurotransmitters, such as serotonin, gamma-aminobutyric acid (GABA), acetylcholine, dopamine, histamine, glutamate and noradrenaline, preserving the CNS from overstimulation or over-inhibition that may be caused by other neurotransmitters.

CB2 receptors are expressed predominantly in cells of the immune system [31] and hematopoietic, but more recently their presence has been detected in the brain, in particular microglial cells, though at low concentrations [32]. It is well known that in response to damaging events, such as neuro-inflammation and cerebral hypoxia-ischemia, microglial cells may upregulate CB2 receptors expression in brain. Indeed, $\mathrm{CB} 2$ receptors exhibit potent anti-inflammatory effects modulating the release of cytokines [33,34].

Both CB1 and CB2 receptors belong to the family of G-protein coupled receptors (GPCRs) that, after cannabinoid agonist binding and signaling, exert an inhibitory effect on adenylate cyclase activity [35,36]. This inhibits the conversion to cyclic adenosine triphosphate (ATP) to cAMP, an important cellular secondary messenger involved in the mechanisms of signal transduction, which activates kinase protein $A$ (PKA).

$\mathrm{CB} 1$ and $\mathrm{CB} 2$ receptors signaling leads to the downstream activation of all mitogen-activated protein kinase (MAPK), p44/42, p38 and c-JUN amino terminal kinase, which can regulate nuclear transcription factors. Also, their activation is strictly linked to ion channel regulation by inhibition of calcium channels and activation of potassium channels [37].

There is increasing evidence supporting the existence of additional cannabinoid receptors (no-CB1 and no-CB2) in both central and peripheral system, identified in CB1 and CB2- knockout mice [38,39]. Indeed, some actions of certain cannabinoid ligands seems that are mediated by other receptors like transient receptor potential vanilloid type 1 (TRPV1), G protein-coupled receptor 55 (GPR55), G protein-coupled receptor 18 (GPR18), G protein-coupled receptor 119 (GPR119) and 5-hydroxytryptamine receptor subtype 1A (5-HT1A). 
TRPV1 is a non-selective cation channel for calcium, magnesium and sodium ions. It exhibits various activation and modulatory mechanisms, involving in the stimulation by GPCRs, noxious heat, low $\mathrm{pH}$, and various endogenous cannabinoids such as anandamide (AEA), 12-hydroperoxy-eicosatetraenoic acid (12-HPETE) and N-arachidonoyl dopamine (NADA) [40]. Also, TRPV1 receptors play a role in transmission and modulation of nociception, as well as the integration of diverse painful stimuli [41]. They are found mainly in the nociceptive neurons of the peripheral nervous system, but they have also been described in CNS, specifically, in the hippocampus, cortex, and substantia nigra [42,43].

Orphan GPCRs, most notably GPR55, GPR18 and GPR119 have been proposed as potential novel cannabinoid receptors [44]. GPR55 is widely expressed in the brain, especially in the cerebellum. GPR55 can be characterized as a cannabinoid receptor, on the basis of sequence homology at the binding site, in fact the encoded integral membrane protein is a likely CB1 and CB2 cannabinoid receptors [45]. Also, it was demonstrated that GPR55 responds to a variety of both endogenous and exogenous cannabinoid ligands, such as $\Delta^{9}$-THC, CP55940 (CB1 and CB2 agonist), AEA and virodhamine [46] as do the cannabinoid receptors. These features led to suggest GPR55 as a putative third cannabinoid receptor [46,47]. GPR55 may be involved in several physiological and pathological processes by activating a variety of signal transduction pathways [48]. Combining with an extracellular signal and transmitting the signal across the membrane by activating an associated G-protein, promotes the exchange of GDP for GTP on the alpha subunit of a heterotrimeric G-protein complex. Also its activation promotes activation of the small $\mathrm{G}$ proteins rhoA, cdc42 and rac1 and a transduction mediated by the ERK1 and ERK2 cascade [49,50].

Recently a fourth potential receptor GPR18 activated by N-arachidonoylglycine (NAGly), a metabolite of AEA, has also been described [51]. GPR18 is expressed in gastrointestinal, immune and testicular tissues, as well as the striatum, cerebellum and brain stem [52]. Also, GPR18 is found on microglial cells in the brain where it regulates the migration of these cells following CNS damage or inflammation [51].

GPR119 is another orphan receptor originally identified in genome-sequencing efforts and expressed predominantly in the pancreas and gastrointestinal tract [53]. The identification of GPR119 as a putative cannabinoid receptor comes from reports of activation of GPR119 by oleoylethanolamide, a monounsaturated analogue and functional antagonist of AEA [54], although controversy remains on its physiological role.

5-HT1A receptor is a subtype of serotonin receptor expressed both as a presynaptic autoreceptor on raphè neurons, and as a major postsynaptic receptor in several brain regions including cerebral cortex, amygdala and hippocampus involved in mood, memory, emotion and stress response [55]. Activation of both pre- and postsynaptic 5-HT1a receptors decreases neuronal excitability [56,57] Also, 5-HT1A is a GPCR that inhibits adenylate cyclase and activate receptor operated potassium channel, whereas inhibits voltage gated calcium channel [58].

Particularly, it was demonstrated that CBD exerts many of its effects by binding 5-HT1A receptor. Activation of this receptor in key brain areas related to defensive responses, including the dorsal paeriaqueductal grey, bed nucleus of the stria terminalis and medial prefrontal cortex, leads to anxiolytic, antidepressant and antipsychotic effects showed by CBD [59].

$\Delta^{9}$-THC, of which are well-known psychotropic effects, is believed to perform the majority of its actions in the CNS binding CB1 and CB2 receptors [60]. Non-psychotrophic phytocannabinoids (CBD, 
$\mathrm{CBG}, \mathrm{CBC}, \Delta^{9}$-THCV and CBDV), exert multiple pharmacological effects via $\mathrm{CB} 1 / \mathrm{CB} 2$ receptors as well as no-CB1 and no-CB2 receptors [50] involving intracellular pathways that play a key role in neuronal physiology. These compounds, especially CBD, are able to suppress the production of a wide range of pro-inflammatory cytokines, such as tumor necrosis factor (TNF)- $\alpha$ and interleukin (IL-) $1 \beta$ [61,62]. They show also a potent action in inhibiting oxidative and nitrosative stress, modulating the expression of inducibile nitric oxide synthase (iNOS) and reducing the production of reactive oxygen species (ROS) [63]. Moreover, non-psychotrophic phytocannabinoids attenuate high-glucose-induced mitochondrialsuperoxide generation and NF- $\kappa B$ activation, along with the expression of intercellular adhesion molecule 1 (ICAM-1) and vascular cell adhesion molecule (VCAM-1) [64]. Together, these activities suggest that these compounds can exert neuroprotective, antioxidant and anti-inflammatory effects.

Figure 4 summarizes the mechanisms of action and cannabinoid-induced cellular signaling in the neurological diseases investigated.

Figure 4. Cannabinoid-induced cellular signaling in neurologic disease.

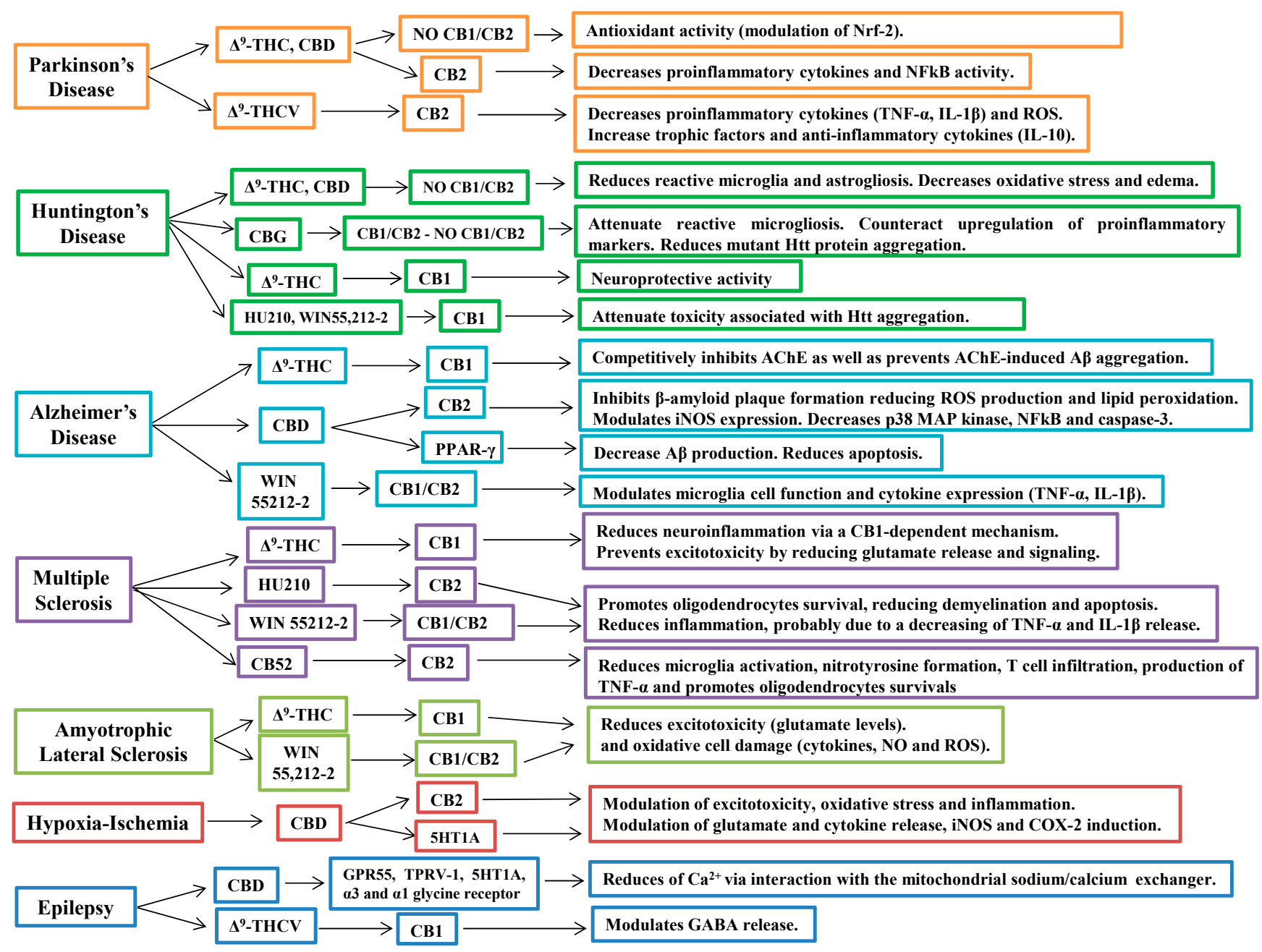

Therapeutic properties of $\mathrm{CB}$ receptor agonists and antagonists have been proposed for the treatment of different human disorders by preclinical and clinical observations. Interactions at CB1 and/or CB2 sites appear to affect molecular mechanisms that are responsible for disease onset or progression. 


\section{Cannabinoids in the Treatment of Neurodegenerative Diseases}

Neurodegenerative diseases are chronic and progressive disorders characterized by the gradual loss of neurons in discrete areas of the CNS. Parkinson's disease (PD), Huntington's disease (HD), Alzheimer's disease (AD), multiple sclerosis (MS), amyotrophic lateral sclerosis (ALS) and cerebral ischemia are considered the disorders with the highest incidence in the population worldwide.

While the etiopathogenesis of these diseases is different, a number of common mechanisms underlying their progressive nature have been elucidated, such as neuro-inflammation, oxidative stress, excitotoxicity, protein misfolding and mitochondrial dysfunction.

Nowadays, for these diseases there is no cure, current therapies have focused on treatment of symptoms and try to delay their progression. It has been demonstrated that endocannabinoid signaling is alterated in many neurodegenerative diseases [65]. Therefore, it is believed that modulation of the endocannabinoid system could be a useful alternative in neurodegeneration treatment. Furthermore, preclinical research from animal models of neurodegeneration and clinical trials have suggested a potential role of cannabinoids in the attenuation of inflammation and the protection of neurons at risk of damage. Below we reported the most significant data regarding the current status of therapeutic effects of cannabinoids in neurodegenerative disease management.

\subsection{Cannabinoids in Parkinson's Disease}

PD is a chronic, progressive neurodegenerative disorder, characterized by the progressive degeneration of dopaminergic neurons in the substantia nigra pars compacta and consequent reduction in dopamine (DA) content in striatum [66]. The enzyme tyrosine hydroxylase (TH) present in all dopaminergic cells, catalyzes the formation of L-DOPA, the rate-limiting step in the biosynthesis of DA, thereby directly linking PD with TH [67]. Thus, a TH deficiency in the striatum is a hallmark of PD [68].

The death of nigral dopaminergic neurons leads to the typical motor symptoms observed in PD, bradykinesia, tremor, and rigidity.

Several experimental and clinical studies have demonstrated that endocannabinoid system undergo evident neurochemical and neurophysiological alterations after dopamine depletion [69-72]. In fact, as consequence of reduction in dopaminergic signaling, endocannabinoids levels as well as CB1 receptor expression result to be up-regulated in basal ganglia [73,74], suggesting that cannabinoids could have a therapeutic role in the treatment of movement disorders associated with PD.

To better understand what is the cannabinoid mechanism of action in PD and their antiglutamatergic effects, it is vital to explain the network of synapses involved in the genesis and in the control of voluntary and involuntary movements. For this purpose, it will be beneficial to summarize and comment on mechanism prospects outlined by many authors [75-77].

At level of basal ganglia, when the prefrontal sensorial cortex receives a stimulus to perform a movement, sensitive cortical neurons send glutamatergic excitatory signals to striatum nucleus (putamen) that, via GABAergic neurons, inhibits the activity of internal globus pallidus. This is known as the direct pathway of movement control. So doing, the GABAergic inhibitory signal of globus pallidus, that normally controls the activity of thalamic nucleus, is lost and thalamus can send an excitatory glutamatergic signal to motor cortex that perform the movement. 
There is also an indirect pathway triggered from putamen: GABAergic neurons project to external globus pallidus that is inhibited to send, in turn, its GABAergic inhibitory signal to subthalamic nucleus. Subthalamic nucleus can now activate three pathway trough glutamatergic excitatory signals direct to: (1) substantia nigra pars reticulate; (2) internal segment of globus pallidus; (3) substantia nigra pars compacta. Among them, substantia nigra pars compacta is crucial to release dopamine neurotrasmitter activating striatum that stimulates the triggering of direct pathway via D1 receptors and, parallel, the inhibition of indirect pathway via D2 receptors. In PD, a depletion of dopamine in the striatum causes a cascade that lead to invert the normal balanced functioning of the basal ganglia circuitry. All this cascade of events lead to the blocking of the direct pathway and to the activation of the indirect pathway, so that we have bradykinesia as well as distorted muscle movements characteristic of PD patients.

Overall, the results is a disinhibition of the striatal neurons and therefore a relative glutamatergic overactivity, that antiglutamatergic therapies with cannabinoids counteract, mostly via $\mathrm{CB} 1$ receptor sited at level of presynaptic region of glutamatergic terminal [78].

More in detail, since the glutamatergic excitation is mediated by N-methyl-D-aspartate (NMDA) receptors of the neurons sited in the striatum and subthalamic nucleus, antagonists of NMDA receptors could reduce activity through the indirect pathway [77]. The result of cannabinoids action is translated in a reduction of glutamate release, decreasing calcium influx, as well as of local inflammatory events.

Current therapeutic strategies aim to increase dopaminergic transmission in basal ganglia by administration of dopamine precursors, such as L-DOPA [79], however, in a proportion of patients the efficacy of the treatment declines through time.

The majority of PD patients undergoing levodopa therapy develop disabling motor complications (dyskinesias) within 10 years of treatment. Recent studies in animal models and in the clinic propose that $\mathrm{CB} 1$ receptor antagonists could prove useful in the treatment of both Parkinsonian symptoms and levodopa-induced dyskinesia, whereas $\mathrm{CB} 1$ receptor agonists could have a role in reducing levodopa-induced dyskinesia (LID) [69].

In reserpine rat model of $\mathrm{PD}$, the dopamine D2 receptor agonist quinpirole led to a significant reduction of akinesia [80]. This effect was substantially reduced by coinjection with the cannabinoid $\mathrm{CB} 1 / \mathrm{CB} 2$ receptor agonist WIN 55,212-2. The concomitant administration of the CB1 antagonist rimonabant (SR141716A) with quinpirole and WIN 55,212-2 blocked the effect of WIN 55,212-2 on quinpirole-induced reduction of akinesia [80]. This suggests that cannabinoid antagonists might be therapeutically advantageous together with dopamine agonists in reversing the endocannabinoid effects upon inhibitory motor function observed in PD.

In Lastres-Becker et al. [81] study, PD was induced in rats injected stereotaxically with a 6-hydroxydopamine (6-OHDA), and then administered for two weeks with $\Delta^{9}$-THC and CBD.The authors found that both compounds were equally effective in protecting nigrostriatal dopaminergic neurons from the neurotoxin 6-OHDA. Also, it was shown that CBD can attenuate dopamine depletion and $\mathrm{TH}$ deficits, which are indicative of the degree of neurodegeneration of nigrostriatal dopaminergic projections [81]. These cannabinoids may function as neuroprotective agents in PD due to their capability to reduce oxidative stress. $\Delta^{9}$-THC and CBD might restore the balance between the excessive production of ROS and a relative deficiency in antioxidant properties by acting as ROS scavengers as well as improving antioxidant enzymes through the activation of signaling triggered by nuclear factor-erythroid 2 (Nfr-2) [82]. 
Also, CBD showed anti-inflammatory properties, reducing the generation of pro-inflammatory cytokines, such as TNF- $\alpha$ and IL-1 $\beta$, as well as ROS and anti-inflammatory cytokines like IL-10 [83].

Moreover, $\Delta^{9}$-THCV has been shown to have neuroprotective effects, both in rats subjected to injection of 6-OHDA [84] as well as in mice injected with lipopolysaccharide (LPS) [84], possibly mediated through its antioxidant effects as well as through upregulation of CB2 receptors, and can therefore affect microglia activation. Also, in both models of PD, it was demonstrated that administration of $\Delta^{9}$-THCV delayed disease progression, reducing motor inhibition, presumably through changes in glutamatergic transmission [84].

However, despite the encouraging data achieved on the potential therapeutic utility of cannabinoids in PD rodent models, studies with non human 1-methyl-4phenyl-1,2,3,6-tetrahydropyridine (MPTP)-lesioned primates have also produced conflicting results.

It was been demonstrated that the therapy with plant-derived cannabinoid agonists for attenuating hypokinetic signs was useless and did not alleviate motor deficits $[85,86]$. In MTPT-treated common marmosets, the blockade of CB1 receptors with SR141716A (rimonabant), a cannabinoid CB1 receptor antagonist, reduced LID without affecting the anti-Parkinsonism efficacy of L-DOPA [87]. Similarly, Meschler et al. [88] using cynomolgus monkeys (Macaca fascicularis), confirmed that SR141716A did not improve motor disability. Also in the same study it was demonstrated that cannabinoid agonist levonantradol produced a decrease in locomotor activity and an increase in bradykinesia in primates. Also, cannabinoid agonists did not induce catalepsy in primates, a property that differs from their effects in rodents [88].

Furthermore, as for the animal studies, drug trials in PD patients have produced conflicting results. In a randomized, double-blind, placebo-controlled study the cannabinoid receptor agonist significantly reduced LID in PD [89]. On the contrary, in a double-blind, cross-over study, Cannabis extracts, while well tolerated, did not show effects on LID [90].

\subsection{Cannabinoids in Huntington's Disease}

Huntington's disease (HD) is an autosomal-dominant inherited disorder characterized by striatal neurodegeneration. Literature reports that the cause of the disease is a mutation in the huntingtin (HTT) gene consisting of a CAG triplet repeat expansion translated into an abnormal polyglutamine (polyQ) tract in the amino-terminal portion of huntingtin (Htt) protein [91]. Htt aggregation and its accumulation are extremely toxic for striatal and cortical neuronal subpopulations [92-94]. The loss of motor inhibition that follows results in an evident abnormal and involuntary writhing, commonly defined as "choreiform" movements [95], associated with dementia [96] and cognitive impairment [97].

The brain region to which is ascribed the pathology is the corpus striatum that has the functional role to control both posture and gait via GABA neurons that project to globus pallidus and zona reticulata of the substantia nigra, controlling in turn subthalamic nucleus. So doing, it inhibits or gates inappropriate or uncontrolled movements $[98,99]$.

About neuroprotective effects of cannabinoid compounds in experimental HD, three mechanism of neuroprotection have been hypothesized: CB1-dependent, CB2-dependent and CB1-/CB2-independent [96]. The first hypothesis is corroborated by the fact that $\mathrm{CB} 1$ receptor is early down-regulated in ongoing disease, even in asymptomatic phases, so that CB1 receptor loss could have a role in HD pathogenesis [96]. 
The second hypothesis born from the evidence given by CB2 receptor localization. It was observed that it is poorly expressed in striatal parenchima under healthy condition while it is progressively over-expressed during degenerative events leading to HD. In this circumstance, CB2-activation preserve striatal neurons from inflammatory insults produced by reactive microglial cells, maybe through the release of neurotrophins, anti-inflammatory cytokines and metabolic substrates [100,101].

Finally, the CB1-/CB2-independent pathway, involved in the neuroprotection during experimental models of HD seems related to some cannabinoids with antioxidant properties, such as $\Delta^{9}-\mathrm{THC}$ and CBD, since their particular phenolic structures could exert a scavenger action against ROS. Parallel, there is also the assumption of an intracellular signal regulation via the expression control of antioxidant enzymes of phase II (i.e., Nrf-2/ARE signaling) [96]. On this framework, there are conflicting data and the literature about it is very wide.

From a research on MEDLINE about "Huntington's disease and cannabinoids" we got 61 results, extended to 103 when the search was related to "Huntington's disease and cannabinoid receptor".

Among them, noteworthy was a recent preclinical study published on PNAS on January 2014 performed on R6/2 mouse [102]. It is the most commonly used model of HD. R6/2 mouse expresses exon 1 of the human huntingtin gene with around $150 \mathrm{CAG}$ repeats. It also exhibits a progressive neurological phenotype that mimics many of the features of HD, including choreiform-like movements, involuntary stereotypic movements, tremor, and epileptic seizures [103].

The paper reports that a restricted population of CB1 receptors, and more precisely those located on glutamatergic terminals, play a crucial role in the neuroprotective activity of $\Delta^{9}$-THC and, more in general, of (endo)cannabinoids, so that the authors look at these receptors as a promising target for neuroprotective strategies of therapy during HD [102].

Also, Valdeolivas et al., last September published in Neurotherapeutics, the neuroprotective effects of CBG treatment in two in vivo models of HD, such as R6/2 mutant mouse and 3-nitropropionate (3-NP) acid-lesioned mice [104].

Authors ascribe $\mathrm{CBG}$ effects both to cannabinoid receptor-dependent and/or independent mechanisms. So, in the toxic model of HD authors show the neuroprotective CBG capability to attenuate the reactive microgliosis and to counteract the upregulation of pro-inflammatory markers, while in genetic model of HD they describe a recovery in the deteriorated rotarod performance typical of R6/2 mice, an expression partially normalized by CBG treatment of genes linked to HD, as well as an up-regulation of BDNF, IGF-1 and PPAR $\gamma$ genes. Finally, CBG-treated animals showed a reduction in the aggregation of mutant $\mathrm{Htt}$ protein in striatal parenchyma.

Moreover, a MEDLINE research performed on "Huntington's disease and preclinical study and cannabinoids" gave just two results: "Neuroprotective effects of phytocannabinoid-based medicines in experimental models of Huntington's disease" published in Journal of Neuroscience Research in September 2011 [105] and the other one entitled "Sativex-like combination of phytocannabinoids is neuroprotective in malonate-lesioned rats, an inflammatory model of Huntington's disease: role of CB1 and CB2 receptors" published on ACS Chemical Neuroscience in May 2012 [106].

The first study tests a 1:1 botanical combination of extracts enriched in either $\Delta^{9}$-THC or CBD (the main constituents of the cannabis-based drug Sativex ${ }^{\circledR}$ ) on rats stereotaxically subjected to unilateral injection into left striatum of the complex II inhibitor malonate, inducing HD through: (1) increasing the volume of edema; (2) reducing the number of Nissl-stained cells and enhancing the number of 
degenerating cells (3) causing reactive microglia and astrogliosis (4) increasing oxidative stress. According to these authors, the reversion of these effects would be mediated by a CB1 and CB2 receptor-independent mechanism provided by both cannabinoids [106].

Differently by other studies, but in accordance with evidences also reported by Fernández-Ruiz et al. [107], the above-reported study ascribes a balanced role to CB1/CB2 receptors with a likely involvement in drug treatment showing an up-regulation of $\mathrm{CB} 2$ followed by a down-regulation of CB1 receptors, suggesting that $\mathrm{CB} 2$ receptors could play a particularly important role in the protective effect of Sativex ${ }^{\circledR}$.

Furthermore, about synthetic cannabinoids HU210 and WIN 55,212-2, they seems to work in transgenic R6/1 mice, expressing exon 1 of the human HD gene carrying a 115 CAG repeat, through a mechanism mediated by G-protein alpha subtype i/o (G(i/o))-linked and ERK-dependent signal transduction [108]. This promotes the coupling of CB1 receptors to Gi/o and attenuate toxicity associated with Htt aggregation [108].

Despite the encouraging results obtained by the experimental investigations about the potential therapeutic use of cannabinoids in HD symptoms management, clinical trials have not confirmed these results. Particularly, studies performed using cannabinoids have not shown expected improvement in the hyperkinetic symptoms of HD. Consroe et al. [109] published one of the first clinical trials in which CBD was evaluated for symptomatic efficacy and safety in 15 neuroleptic-free patients with HD. Authors demonstrated that CBD, was neither symptomatically effective nor toxic in these patients. Also, in literature, are reported two uncontrolled, single patient studies evaluating efficacy of nabilone, but these studies yielded conflicting results for reducing chorea severity [110,111]. Thus, although nabilone induced signs of improvement in one of these studies, in the other study [110] it made symptoms worse [111]. Nabilone was also used in a double-blind, placebo controlled, cross-over study in which it induced improvements in motor and cognitive indices [112].

The data obtained recently in animal models led to suggest that the combination of different cannabinoids, such as Sativex ${ }^{\circledR}$ may be an interesting tool for developing novel therapies in HD although to date there have been no results.

\subsection{Cannabinoids in Alzheimer's Disease}

$\mathrm{AD}$ is the most frequently form of dementia, with an incidence of about 34 million people worldwide [113]. AD is characterized by lesions in CNS due to the formation of beta-amyloid (A $\beta$ ) plaques, neurofibrillary tangles and cortical atrophy $[114,115]$.

It has been demonstrated that in microglia of $\mathrm{AD}$ patients, $\mathrm{CB} 1$ and $\mathrm{CB} 2$ receptor expression is significantly increased, while in basal ganglia and hippocampus neuronal CB1 receptor expression is decreased [116]. Therefore, endocannabinoid system might play an important role in AD pathogenesis.

To date, the majority of drugs in use for AD treatment are acetylcholine esterase (AChE) inhibitors. According to Eubanks and colleagues [117], $\Delta^{9}$-THC competitively inhibits enzyme AChE and prevents $\mathrm{A} \beta$ peptide aggregation in the brains of Alzheimer patients.

In rat pheocromocytoma $\mathrm{PC} 12$ cells and in vivo models, it was shown that CBD also inhibits $\beta$-amyloid plaques formation, reducing ROS production and lipid peroxidation [118]. 
Also, using mice inoculated with human $A \beta$ (1-42) peptide into the right dorsal hippocampus, Esposito et al. [119] have demonstrated anti-inflammatory and antioxidant actions of CBD. Indeed, CBD is able to attenuate a $\beta$-amyloid plaques formation modulating iNOS expression and also decreasing p38MAP kinase and NF- $\kappa$ B levels. Thus, limiting propagation of neuro-inflammation and oxidative stress.

In addition, Martin-Moreno and colleagues [120] have showed that in A $\beta$-mice, CBD and synthetic cannabinoid WIN 55,212-2 are able to modulate microglial cell function and cytokine expression, improving learning behavior.

Also, CBD appears able to exert a beneficial effect in the amyloidogenic pathway, through a specific molecular mechanism involving peroxisome proliferator-activated receptor- $\gamma$ (PPAR $\gamma$ ) [121]. Scuderi et al. [121] investigated CBD as a possible modulating compound of amyloid precursor protein (APP) in transfected human neuroblastoma SHSY5Y $\mathrm{YPP}^{\mathrm{AP}}$ cells. Achieved results indicated the CBD capacity to induce the ubiquitination of APP protein, which led to a substantial decrease in APP full length protein levels in SHSY5 $\mathrm{Y}^{\mathrm{APP}+}$ with the consequent decrease in $\mathrm{A} \beta$ production. As consequence, CBD has promoted an increased survival of SHSY $5 \mathrm{Y}^{\mathrm{APP}+}$ cells reducing their apoptotic rate and increasing their survival in long-term period of cell culture. All CBD effects showed were dependent on the selective activation of PPAR $\gamma[121]$.

In a recent paper, Aso and co-workers [122] tested the therapeutic properties of combination of $\Delta^{9}-\mathrm{THC}+\mathrm{CBD}(0.75 \mathrm{mg} / \mathrm{kg}$ each $)$ in a A $\beta P P / P S 1$ transgenic mice, an experimental model of $\mathrm{AD}$, which replicates the most relevant features of disease, including cognitive impairment and several pathological alterations, such as $\mathrm{A} \beta$ deposition, dystrophic neurites, synaptic failure, mitochondrial dysfunction, and oxidative stress damage. Authors demonstrated that mixture of the two compounds preserved memory and reduced learning impairment in A $\beta \mathrm{PP} / \mathrm{PS} 1$ transgenic mice when chronically administered during the early symptomatic stage [122].

A significant decrease in soluble $\mathrm{A} \beta$ (1-42) peptide levels and a change in plaques composition were also observed in $\Delta^{9}-\mathrm{THC}+\mathrm{CBD}$-treated $\mathrm{A} \beta \mathrm{PP} / \mathrm{PS} 1$ transgenic mice, due to a reduced microgliosis and expression of several cytokines and related molecules of neuro-inflammation [122]. In this study authors suggest that combination of $\Delta^{9}-\mathrm{THC}+\mathrm{CBD}$ exhibits a better beneficial effect than each Cannabis component alone and support the consideration of a Cannabis-based medicine as potential therapy in $\mathrm{AD}[122]$.

Currently, there are only limited data displaying clinical effects of phytocannabinoids on human AD. A single, open-label, non-placebo controlled study [123] performed with AD patients reported that Dronabinol derived from $\Delta^{9}$-THC has a beneficial role in reducing anorexia and improving behavior, like nocturnal motor activity and agitation.

Despite these encouraging results, the usefulness of cannabinoid based medicines for the treatment of $\mathrm{AD}$ awaits the results of severe clinical trials. Also, to date there are no significant data reported in the literature on the use of phytocannabinoids in the treatment of vascular dementia.

\subsection{Cannabinoids in Multiple Sclerosis}

MS is an autoimmune inflammatory neurodegenerative disease characterized by nerves demyelination in CNS [124]. However its etiology is still unknown. Therefore, in order to better understand the etiopathogenesis of MS and to find new therapeutic strategies, researchers use some experimental 
models. The most used is the experimental autoimmune encephalomyelitis (EAE), which mimics the main features of human MS.

Numerous studies have been performed to evaluate the role of cannabinoids on treatment of EAE-associated spasticity as well as on modulation of the neurodegenerative process.

According to a study performed using CB1-knockout mice, it was demonstrated that the mechanism of improvement spasticity was dependent on CB1 receptors, not CB2 [125]. Also, $\Delta^{9}-$ THC was reported to delay or prevent signs of spasticity in EAE mice, as well as increasing survival rates and reducing neuro-inflammation via a CB1-dependent mechanism [126].

Using synthetic cannabinoid agonists of CB1 and CB2 receptors, such as dexanabinol (HU210, (-)-1,1-dimethylheptyl analog of 11-hydroxy- $\Delta^{8}$-THC) and WIN 55,212-2 in EAE mice, it was demonstrated that they promote oligodendrocytes survival via $\mathrm{CB} 1$ and $\mathrm{CB} 2$ receptor-mediated effects, potentially reducing demyelination and apoptosis $[127,128]$. Also, these cannabinoids were able to reduce inflammation, probably by suppression of TNF- $\alpha$ and IL-1 $\beta$ and enhances the release of anti-inflammatory cytokines such as IL-10 in brain and peripheral blood [129]. Same results were confirmed by Arevalo-Martin et al. [130], using Theiler's murine encephalomyelitis virus-induced demielinating disease (TMEV-IDD) model of chronic-progressive MS. Indeed, it was demonstrated that systemic treatment with synthetic cannabinoid CB1/CB2 receptor agonist WIN 55,212-2 in TMEV-IDD mice can limit axonal loss and neuro-inflammation in animal models of MS, by modulating microglia and lymphocytre infiltration in spinal cord [130].

Also, it was demonstrated that CB52, a newly developed cannabinoid compound (AEA and $\Delta^{9}$-THC hybrid), is more effective than other commonly used cannabinoids and its protection on oligodendrocytes is mediated by the activation of the $\mathrm{CB} 2$ receptor [131].

Using EAE mice, Ribeiro et al. [131], proved that CB52 reduced microglia activation, nitrotyrosine formation, $\mathrm{T}$ cell infiltration, production of TNF- $\alpha$, oligodendrocyte toxicity, myelin loss and axonal damage in the mouse spinal cord white matter and alleviates the clinical scores when given either before or after disease onset.

Moreover, significant alterations of the endocannabinoid system have been found in the brain of EAE and Chronic Relapsing Experimental Allergic Encephalomyelitis (CREAE) mice. Particularly, increased levels of AEA and 2-arachidonoyl glycerol (2-AG), were detected in areas associated with nerve damage in CREAE [4] and in EAE [132], when compared to non-spastic mice.

Also, reduced CB1 expression was showed during acute phases of CREAE [133] and CB2 transcription may be increased in EAE [33]. Administration of SR141716A and SR144528, CB1 and CB2 antagonists, has been shown to worsen tremor and spasticity in CREAE mice, whilst WIN 55,212-2, methanandamide and JWH-133 CB2 agonists reduced both tremor and spasticity in diseased mice [134,135]. In addition, spasticity could also be ameliorated by the inhibition of AEA reuptake and enzymatic hydrolysis, causing a subsequent increase in AEA concentration in the CNS [4].

As well-known endocannabinoids are to be released in response to a wide range of neuronal insults [136], and levels are increased in the CSF and peripheral lymphocytes of patients with MS [137]. Centonze et al. [137] indeed reported a relevant increase in AEA, but not 2-AG levels, in the CSF of relapsing-remitting MS patients experiencing current relapse with a strong correlation between AEA levels and the number of inflammatory lesions visible on imaging. AEA concentrations were also higher in peripheral lymphocytes of these patients; an effect associated with increased synthesis and reduced 
degradation of this endocannabinoid [137]. Another study also showed elevated AEA levels in MS patients when compared with healthy controls, across the clinical spectrum, this time in the plasma, again suggesting that the peripheral endocannabiboid system ma reflect those occurring centrally [138].

Benefits from cannabinoids use seen in animal studies have also been shown in the treatment of MS patients suffering spasticity, with a significant associated disability and quality of life impairment. It is clear that spasticity results from alterations in the balance, possibly secondary to selective neuronal loss, between excitatory and inhibitory neural circuits. Under physiological conditions, inhibitory signals are sent via the corticospinal tract to the spinal cord, but following injury, damage to the corticospinal tract, causes disinhibition of the stretch reflex, leading to reduction in the triggering threshold. This leads to loss of control of neurotransmission between muscles and CNS, resulting in uncontrolled spastic movement [139].

Current therapies for spasticity include GABA receptor agonist, baclofen, tizanidine, benzodiazepine and anxioltyics [140]. Also, local administration of botulinum toxin have also shown efficacy in clinical trials [140]. The use of phytocannabinoids may be useful in MS patients, which show resistance to these conventional therapies, as shown in clinical studies reported in literature.

The Cannabinoids in MS (CAMS) study [141], a double-blind, randomized, placebo-controlled trial, was the first large-scale study designed to test the hypothesis that cannabinoids may have a beneficial effect on spasticity associated with MS. This study involved $630 \mathrm{MS}$ patients treated with dronabinol (a synthetic $\Delta^{9}$-THC), cannador (2.5 mg of $\Delta^{9}$-THC, $1.25 \mathrm{mg}$ of CBD, and $5 \%$ of elements other than cannabinoids per capsule) and placebo. It did not show any significant improvement in spasticity at 15 weeks [141], but this was evinced with both Cannabis compounds after one year of treatment [142]. Also, MS patients perceived a significant improvement in pain and sleep disorders [142]. Other studies performed with smaller numbers of patients and crossover studies [14] have confirmed the same results previously obtained.

Following CAMS study, comes the Cannabinoids Use in Progressive Inflammatory brain Disease (CUPID) study [143], another double-blind, randomized, placebo-controlled trial (duration of three years) in United Kingdom involving 493 patients with progressive MS. The full results from this study are pending, but initial data shows that dronabinol has no overall effect on MS progression, measured with the Expanded Disability Status Scale (EDSS) scale.

Analysis of a subgroup of patients in this study suggested a possible benefit from dronabinol in those who began the trial with milder disability, but not in those who began the trial with more severe disability [143].

A recent randomized, double-blind, placebo-controlled study involving 15 relapsing-remitting MS patients with MS-induced neurophatic pain was conducted to evaluate Nabilone combined with gabapentin. Results suggest that Nabilone as an adjunctive to gabapentin is an effective, well-tolerated combination for MS-induced neurophatic pain and thus can be used as a novel therapeutic combination in MS treatment [144].

In addition, use of Sativex ${ }^{\circledR}$ has been extensively investigated in the management of patients with MS $[14,15]$. Currently, this spray preparation is used as treatment to alleviate symptoms of spasticity and neurophatic pain in adult MS patients that did not show an appropriate response to other drugs during an initial trial period of therapy. It has also been reported that Sativex ${ }^{\circledR}$ shows efficacy in the treatment of bladder dysfunction, frequent in MS patients, showing a decrease of incontinence episodes and an 
increase in bladder retention volume. According to another study [145], MS patients treated with Cannabis extract; $\Delta^{9}$-THC, showed an important reduction in events of urge incontinence compared to placebo. Thus, suggesting that phytocannabinoids might compensate for the bladder neural circuitry disregulation that often accompanies disease progression in MS.

Spasticity, neuropathic pain and uncontrollable bladder and bowel are symptoms observed also in patients affected by spinal cord injury (SCI).

Therefore, use of cannabinoids and mixture of extracts could be useful in treatment of this pathology. Unfortunately, in the literature there are only a few studies that do not report interesting data.

\subsection{Cannabinoids in Amyotrophic Lateral Sclerosis}

ALS is the most prevalent form of motoneuron disease, characterized by degeneration and death of motor neuron populations in the cerebral cortex, brainstem and spinal cord [146]. Several mechanisms have been involved in ALS pathogenesis, such as neuro-inflammation, mostly mediated by excitotoxicity and oxidative damage on motor neurons [147,148].

There is rapidly emerging evidence that the cannabinoid receptor system has the potential to reduce both excitotoxic and oxidative cell damage.

Numerous studies reported in literature, have been conducted using ALS hSOD(G93A) transgenic mice, the strain predominantly used. Indeed, the disease in these animals closely mimics human ALS.

It was shown that mice treated with $\Delta^{9}$-THC exhibited an improvement of motor impairment by administration of the molecule, either before or after signs onset, a prolonged survival by $5 \%$ [149]. According to Bilsland et al. [150], a significant delay was found in disease progression when CB1/CB2 receptor agonist WIN 55,212-2 was administered to ALS hSOD(G93A) mice beginning after onset of motor impairment and tremor (at 90 days old), however, survival was not extended.

Furthermore, using the same experimental model of ALS, it was demonstrated that CB1 deletion, had no effects on disease onset, but extend lifespan by 15 days, a $13 \%$ increase in survival [150].

Also, it is important determining CB2 receptor role, since microglia from ALS hSOD(G93A) mice seems to possess increased cytotoxic potential [151]. Indeed, CB2 activation blocks $\beta$-amyloid induced microglia activation [152]. On the contrary, with other stimuli, CB2 activation showed increasing microglial migration and proliferation.

Using selective CB2 agonist, AM1241, it was reported that ALS hSOD(G93A) mice showed slowing of disease progression if administered after disease onset [153]. Administration at the onset of tremors delayed motor impairment in treated mice when compared with vehicle controls. Also, in these mice an increase of $56 \%$ in survival interval was shown [153].

In a recent study, Moreno-Martet et al. [154] evaluated neuroprotective effects of Sativex ${ }^{\circledR}$ in $\mathrm{SOD}(\mathrm{G} 93 \mathrm{~A})$ transgenic mice. Sativex ${ }^{\circledR}$ has proven to be effective in delaying ALS progression in the early stages of disease and in animal survival, although the efficacy was decreased during progression of disease. Also, it has been demonstrated that changes occur in endocannabinoid signaling, particularly a marked up-regulation of CB2 receptors in $\operatorname{SOD}(\mathrm{G} 93 \mathrm{~A})$ transgenic mice. Thus, Sativex ${ }^{\circledR}$ may be used as an adjunctive therapy with only one medicine already approved, Rilutek ${ }^{\circledR}$, which shows modest efficacy on disease progression. 
To date, there have been few studies on human ALS. According to Yiangou et al. [155], in human ALS patients, spinal cord demonstrates motor neurons damages marked by CB2-positive microglia/macrophages. Moreover, a recent study analyzing activated microglia from spinal cord in human ALS patients demonstrated a CB2 increase. So all these data show how editing CB2-mediated processes could change ALS progression and how much the endocannabinoid system is potentially involved in reducing neuro-inflammation, excitotoxic, and oxidative cell damage [156].

Finally, in literature it has been reported in a single case study of patients with ALS, the $10 \%$ who admitted consuming Cannabis, have reported moderate relief of several symptoms, including appetite loss, depression, spasticity and drooling [157].

\subsection{Cannabinoids in Cerebral Ischemia and Hypoxia}

Ischemia is the result of a transient or permanent reduction in cerebral blood flow caused by occlusion of a cerebral artery via an embolus or local thrombosis, sufficient to alter cerebral functions. This causes a complex sequence of events, including mechanisms of excitotoxicity, release of neurotransmitters, breakdown of blood-brain barrier, inflammation, cytokines production, adhesion molecules upregulation, oxidative and nitrosative stress and programmed neuronal cell death [158-160].

Recently, cannabinoids have emerged as promising neuroprotective agents in several experimental model of brain damage. It seems that the endocannabinoid signaling system has various features for which appears to be involved in ischemic damage. Among these, endocannabinoids and related lipids accumulate in ischemic tissues and play a role in maintaining metabolic homeostasis and responsiveness of the brain to stress [161].

It was demonstrated that CBD can invert brain damage following cerebral ischemia in mice, decreasing brain edema and seizures associated with temporary occlusion of carotid arteries [162]. CBD was able to reduce cerebral hemodynamic impairment and ameliorate brain metabolic activity post-injury [162]. Also, it seems that CBD exerts a neuroprotective effect toward brain ischemia, causing an increase in cerebral blood flow mediated by 5-HT1A receptor and/or be secondary to its cannabinoid receptor-independent anti-inflammatory activity [163].

To date, few studies were carried out in patients with cerebral ischemia, because the limiting factor seems to be that only some compounds results are useful, and only if taken shortly before or within a few hours after cerebral damage. Clinical trials using dexabinol a synthetic $\Delta^{9}$-THC, showed no efficacy in cerebral ischemia treatment [164].

Similarly, the same mechanisms involved in cerebral ischemia, were found in hypoxic-ischemic brain injury events. Frequently, this devastating condition is one of the most important causes of neonatal brain injury and also results in adverse developmental outcomes [165].

To date, there are few reports on the possible neuroprotective effect of cannabinoids in newborns and existing publications consider their beneficial effects against excitotoxicity. CBD demonstrated neuroprotective effects in the brain of newborn Wistar rats following hypoxia-ischemia, associated with the modulation of excitotoxicity, oxidative stress and inflammation [166]. Indeed, CBD modulates glutamate and cytokines release, as well as the induction of iNOS and type 2 cyclooxygenase (COX2) [167]. Also, using a hypoxic-ischemic brain injury model in newborn pigs, Pazos et al. [168] confirmed that CBD modulates these mechanisms acting on CB2 and 5HT1A receptors. 
Moreover, CBD activity was tested in newborn piglets, subjected to temporary occlusion of both carotid arteries plus hypoxia [162]. CBD administration reduced short-term brain damage, in a manner that can be attributed to a CBD-induced reduction of cerebral hemodynamic impairment, improvement of brain metabolic activity post-insult, reduction of brain edema, and reduction of seizures. These neuroprotective effects were not only free from side effects but also associated with some cardiac, hemodynamic, and ventilatory benefits [162].

Therefore, CBD may be considered an important candidate for future clinical trials with hypoxic newborns.

\section{Other Therapeutic Applications of Cannabinoids}

The use of Cannabis has been shown in the treatment of many diseases through time. Among these, treatment of epilepsy seems to be one of the most ancient.

Epilepsy is a chronic neurological disease that affects 50 million people worldwide, characterized by recurrent seizures and often accompanied by cognitive deficits and mood disorders [169]. The targeting of neuronal ion channels and both GABA and glutamate receptors has been the primary approach to eliminate convulsions. Despite the availability of a wide range of antiepileptic drugs, about one-third of individuals with epilepsy still experience seizures that do not to respond to medications [170].

The biological reason to believe that cannabinoids could suppress epileptic seizures is the abundance of CB1 receptors in some areas of the brain (hippocampus and amygdala) where partial seizures originate [171].

Various cannabinoids have been show in several clinical studies to have significant anticonvulsive properties, especially CBD and more recently CBDV and $\Delta^{9}$-THCV [172-174].

The antiepileptic mechanisms of CBD are not well known, since CBD has low affinity for CB1 and $\mathrm{CB} 2$ receptors [23], it seems that $\mathrm{CBD}$ may exert its effects through different mechanisms, including effects on the equilibrative nucleoside transporter, GPR55, TPRV-1, 5-HT1A, and the $\alpha 3$ and $\alpha 1$ glycine receptors. Also, antiepileptic mechanism of action of $\mathrm{CBD}$ might involve a reduction of $\mathrm{Ca}^{2+}$, via interaction with the mitochondrial $\mathrm{Na}^{2+} / \mathrm{Ca}^{2+}$ exchanger [175].

Likewise CBDV and, to a far smaller extent, $\Delta^{9}-\mathrm{THCV}$ produces anticonvulsant effects in animal models of epilepsy. Scutt and Williamson [176] reported that CBDV acts via CB2 cannabinoid receptor-dependent mechanisms but direct $\mathrm{CB} 2$ receptor effects were not shown. Recently, it was also demonstrated by other studies that CBDV acts via non-CB1/CB2 mechanisms. These compounds in fact interact with TRPV1, TRPV2, TRPA1, and TRPM8 channels, but their molecular pharmacology and mechanisms of action are less well known [177].

Additionally, CBDV has been shown to inhibit the primary synthetic enzyme of the endocannabinoid, 2 -arachidonoylglycerol, diacylglycerol lipase $\alpha$ in vitro [178]. While the pharmacological significance of these effects remains unconfirmed in vivo and the targets identified have not yet been linked to epilepsy, they support the emergent role of multiple non-CB receptor targets [179].

Moreover, $\Delta^{9}$-THCV has demonstrated interesting potential use in treatment of convulsions. $\Delta^{9}$-THCV increases, in a GABA antagonist sensitive manner, inhibitory neurotransmission in mouse cerebellum and also exhibits anticonvulsant activity in a rat piriform cortical (PC) model of epilepsy [180]. Possible mechanisms underlying cannabinoid actions in the CNS include CB1 receptor antagonism or inverse agonism at constitutively active CB1 receptors [180]. 
Also, Hill et al. [173] have shown that $\Delta^{9}$-THCV reduced Purkinje cell firing via an increase in inhibitory neurotransmission at interneuron-Purkinje cell synapses in mouse acute parasagittal cerebellar brain slices, most likely by reducing CB1 receptor-mediated, endocannabinoid-induced inhibition of GABA release. Interestingly, $\Delta^{9}-\mathrm{THCV}$ was shown to modulate GABA release onto Purkinje cells at a network level, as it did not affect Purkinje cell spike firing following GABA-receptor blockade [181].

It is well know that CBD has therapeutic potential over a wide range of non-psychiatric and psychiatric diseases, such as anxiety, depression, bipolar disorder, psychosis and sleep disorders.

Although pharmacological effects of CBD in several biological systems have been widely investigated, mechanisms responsible for its therapeutic potential are still not clear. From studies on different animal models, it seems that CBD exerts anxiolytic-like effects by activating post-synaptic 5-HT1A receptors in key brain areas related to defensive responses, including the dorsal periaqueductal grey, bed nucleus of the stria terminalis and medial prefrontal cortex [59,182].

Other effects, such as anti-compulsive, blockade of the anxiogenic consequences of chronic unpredictable stress, increased extinction and impaired reconsolidation of aversive memories, and facilitation of adult hippocampal neurogenesis may depend on potentiation of anandamide-mediated neurotransmission. Activation of TRPV1 channels may be invoked to explain the antipsychotic effect and the bell-shaped dose-response curves commonly observed with CBD [59].

In addition to these mechanisms, CBD can interfere in different other important biological processes (inhibition of adenosine uptake, inverse agonism at CB2, CB1 antagonism, GPR55 antagonist, intracellular $\mathrm{Ca}^{2+}$ increase). Therefore, further studies are needed to investigate their possible involvement on CBD behavioral effects.

Russo et al. [183], reviewed the effects of Cannabis, and highlighted the benefits that can accrue in this regard, particularly with respect to symptom reduction permitting better sleep, as opposed to a mere hypnotic effect. In several clinical studies, it has been found that low doses of Cannabis improve mood, in particular, $\Delta^{9}$-THC increase serotonin levels in the brain, interacting with CB1 receptors.

Therefore, non-psychotropic compounds require further studies to propose these as a potentially useful drug in the treatment of a variety of intractable conditions, at least in association with current conventional therapy.

Finally, cannabinoids have been shown to be potent analgesics in animal models of hyperlgesia and thus might be useful in the treatment of inflammatory pain as well as neuropathic pain [184].

Neuropathic pain is a debilitating form of chronic pain resulting from peripheral nerve injury, toxic insults, and disease states, such as diabetes, cancer, human immunodeficiency virus, MS, and herpes zoster infection [185-187]. Neuropathic pain remains a significant clinical problem because it responds poorly to available therapies, needing validation of novel analgesic drugs. More recently, CBD was shown to be effective in well-established experimental models of neuropathic pain. It is believed that the analgesic effect of CBD is mediated, at least in part, by TRPV1 [188]. There is also evidence to suggest that cannabinoids can induce antinociception via supraspinal mechanisms and peripheral CB2 receptors [189]. Also, the analgesic effects may be mediated in part at the level of spinal cord via CB1 receptors activation [190].

Table 1 summarizes cannabinoid therapeutic targets for each disorder considered. 
Table 1. Therapeutic targets for cannabinoid medicines.

\begin{tabular}{|c|c|c|c|}
\hline Disease & $\begin{array}{l}\text { Therapeutic } \\
\text { Cannabinoids }\end{array}$ & Therapeutic Targets & Ref. \\
\hline \multirow{4}{*}{ PD } & $\Delta^{9}-\mathrm{THC}$ & Tremor & Lastres-Becker et al. [81] \\
\hline & $\mathrm{CBD}$ & Dystonia and discinesia & Lastres-Becker et al. [81] \\
\hline & $\begin{array}{c}\text { WIN 55,212-2 } \\
+ \\
\text { SR141716A } \\
\text { (RIMONABANT) } \\
\end{array}$ & Akinesia & Maneuf et al. [80] \\
\hline & $\Delta^{9}-\mathrm{THCV}$ & Diskinesia & Garcia et al. [84] \\
\hline \multirow{4}{*}{ HD } & $\Delta^{9}-\mathrm{THC}$ & $\begin{array}{l}\text { Hyperkinesia and choreic } \\
\text { movements }\end{array}$ & Chiarlone et al. [102] \\
\hline & CBG & Hyperkinesia & Valdeolivas et al. [104] \\
\hline & $\begin{array}{c}\Delta^{9}-\mathrm{THC}+\mathrm{CBD} \\
\left(\mathrm{SATIVEX}^{\circledR}\right) \\
\end{array}$ & $\begin{array}{c}\text { Hyperkinesia and choreic } \\
\text { movements }\end{array}$ & Sagredo et al. [106] \\
\hline & HU210 and WIN55,212-2 & Hyperkinesia & Scotter et al. [108] \\
\hline \multirow{5}{*}{ AD } & $\Delta^{9}$-THC & $\begin{array}{c}\text { Behavior disorders and motor } \\
\text { impairment }\end{array}$ & Eubanks et al. [117] \\
\hline & CBD & Learning behavior & $\begin{array}{c}\text { Esposito et al. [119]; } \\
\text { Martin-Moreno et al. [120] }\end{array}$ \\
\hline & WIN 55,212-2 & Cognitive impairment & Martin-Moreno et al [120] \\
\hline & $\Delta^{9}-\mathrm{THC}+\mathrm{CBD}$ & $\begin{array}{l}\text { Memory and learning } \\
\text { impairment }\end{array}$ & Aso et al. [122] \\
\hline & $\begin{array}{l}\text { SYNTHETIC } \Delta^{9} \text {-THC } \\
\text { (Dronabinol) }\end{array}$ & $\begin{array}{l}\text { Nocturnal motor activity, } \\
\text { agitation and anorexia }\end{array}$ & Walther et al. [123] \\
\hline \multirow{6}{*}{ MS } & $\Delta^{9}-\mathrm{THC}$ & Spasticity & Lyman et al. [126] \\
\hline & $\begin{array}{l}\text { HU210 and WIN } \\
55,212-2\end{array}$ & Tremor and spasticity & $\begin{array}{l}\text { Molina-Holgado et al. }[127] ; \\
\text { Cabral et al. }[128] ; \\
\text { Arevalo-Martin et al. }[130]\end{array}$ \\
\hline & JWH-133 & Tremor and spasticity & $\begin{array}{c}\text { Baker et al. }[134] ; \\
\text { Buccellato et al. }[135]\end{array}$ \\
\hline & CB52 & Motor impairment & Ribeiro et al. [131] \\
\hline & $\begin{array}{l}\text { SYNTHETIC } \Delta^{9} \text {-THC } \\
\text { (NABILONE) }\end{array}$ & Neuropathic pain & Turcotte et al. [144] \\
\hline & $\begin{array}{c}\Delta^{9}-\mathrm{THC}+\mathrm{CBD} \\
\left(\mathrm{SATIVEX}^{\circledR}\right) \\
\end{array}$ & $\begin{array}{l}\text { Spasticity, neuropathic pain } \\
\text { and bladder dysfunction }\end{array}$ & $\begin{array}{c}\text { Vaney et al. [14]; Wilkinson et al. } \\
\text { [15]; Freeman et al. [145] }\end{array}$ \\
\hline \multirow{4}{*}{ ALS } & $\Delta^{9}-\mathrm{THC}$ & $\begin{array}{l}\text { Motor impairment and } \\
\text { spasticity }\end{array}$ & Raman et al. [149] \\
\hline & WIN 55,212-2 & $\begin{array}{c}\text { Tremor and motor } \\
\text { impairment }\end{array}$ & Bilsland et al. [150] \\
\hline & AM1241 & $\begin{array}{c}\text { Tremor and motor } \\
\text { impairment }\end{array}$ & Kim et al. [153] \\
\hline & $\begin{array}{l}\Delta^{9}-\mathrm{THC}+\mathrm{CBD} \\
\left(\mathrm{SATIVEX}^{\circledR}\right)\end{array}$ & Motor impairment & Moreno-Martet et al. [154] \\
\hline $\begin{array}{c}\text { Cerebral } \\
\text { Ischemia } \\
\text { and Hypoxia } \\
\end{array}$ & CBD & $\begin{array}{l}\text { Reduction of brain edema, } \\
\text { cerebral hemodynamic } \\
\text { impairment and seizures }\end{array}$ & $\begin{array}{l}\text { Alvarez et al. }[162] ; \\
\text { Pazos et al. }[166,168]\end{array}$ \\
\hline \multirow{3}{*}{ Epilepsy } & CBD & Convulsions & Jones et al. [172] \\
\hline & CBDV & Convulsions & $\begin{array}{c}\text { Scutt et al. }[176] ; \\
\text { de Petrocellis et al. [177] }\end{array}$ \\
\hline & $\Delta^{9}-\mathrm{THCV}$ & Convulsions & Dennis et al. [180]; Ma et al. [181] \\
\hline
\end{tabular}




\section{Conclusions}

In this review, we showed how the Cannabis plant, an ancient industrial crop, is drawing increasing attention as a pharmaceutical plant, and is today considered a true "bioreactor" source of botanical raw material from which high amounts of potentially valuable cannabinoids can be extracted. In the future, these molecules will be increasingly used in clinical trials necessary to assess the potential of each phytocannabinoid for the treatment of several diseases, among which CNS disorders.

Whereas, current treatments for CNS diseases are partially effective and have risks of side effects that are not easily tolerated by patients, the development of new synthetic cannabinoids or cannabinoid-derived drugs may represent an alternative strategy to pursue.

The observations from experimental models of neurological diseases, and now increasingly from clinical trials, underline the therapeutic usefulness of cannabinoids-based medicines for treatment of symptoms associated to these. In addition, there is growing evidence from experimental studies that $\Delta^{9}$-THC and other cannabinoids, notably CBD, have neuroprotective effects as a result of their antioxidant, anti-inflammatory and anticytotoxic properties which may prove disease modifying in CNS disorders.

Despite emerging evidence regarding putative therapeutic activities of cannabinoids, their effective introduction in the clinical use is still controversial and strongly limited by unavoidable psychotropic effects, exhibited by many of them.

The possibility of overcoming these side effects and developing novel approaches represents the main open question about the use of cannabinoids as new therapeutic drugs for the treatment of neurological disorders.

\section{Acknowledgments}

The authors would like to thank the Giuseppe Galletta and Massimo Messina belonging to the secretary office of IRCCS Centro Neurolesi "Bonino-Pulejo"-Messina, for their excellent technical assistance.

\section{Author Contributions}

Sabrina Giacoppo performed bibliographic research and drafted and reviewed the manuscript. Giuseppe Mandolino contributed to the manuscript drafting. Galuppo Maria performed bibliographic research and supported manuscript correction. Emanuela Mazzon and Placido Bramanti designed the paper and supervised manuscript drafting.

\section{Conflicts of Interest}

The authors declare no conflict of interest.

\section{References}

1. Sakamoto, K.; Akiyama, Y.; Fukui, K.; Kamada, H.; Satoh, S. Characterization, genome sizes and morphology of sex chromosomes in hemp (Cannabis sativa L.). Cytologia 1998, 63, 459-464. 
2. Mandolino, G. Marker assisted selection and genomics of industrial plants. In Improvement of Crop Plants for Industrial End Uses; Ranalli, P., Ed.; Springer: Dordrecht, The Netherlands, 2007; pp. 59-82.

3. Forapani, S.; Carboni, A.; Paoletti, C.; Moliterni, V.M.C.; Ranalli, P.; Mandolino, G. Comparison of Hemp Varieties Using Random Amplified Polymorphic DNA Markers. Crop. Sci. 2001, 41, $1682-1689$.

4. Baker, D.; Pryce, G.; Croxford, J.L.; Brown, P.; Pertwee, R.G.; Makriyannis, A.; Khanolkar, A.; Layward, L.; Fezza, F.; Bisogno, T.; et al. Endocannabinoids control spasticity in a multiple sclerosis model. FASEB J. 2001, 15, 300-302.

5. Russo, E.B.; Jiang, H.E.; Li, X.; Sutton, A.; Carboni, A.; del Bianco, F.; Mandolino, G.; Potter, D.J.; Zhao, Y.X.; Bera, S.; et al. Phytochemical and genetic analyses of ancient cannabis from Central Asia. J. Exp. Bot. 2008, 59, 4171-4182.

6. Russo, E.B. History of cannabis and its preparations in saga, science, and sobriquet. Chem. Biodivers. 2007, 4, 1614-1648.

7. Russo, E.; Guy, G.W. A tale of two cannabinoids: The therapeutic rationale for combining tetrahydrocannabinol and cannabidiol. Med. Hypotheses 2006, 66, 234-246.

8. Mechoulam, R.; Gaoni, Y.A. Total Synthesis of Dl- $\delta$-1-Tetrahydrocannabinol, the Active Constituent of Hashish. J. Am. Chem. Soc. 1965, 87, 3273-3275.

9. Jackson, S.J.; Diemel, L.T.; Pryce, G.; Baker, D. Cannabinoids and neuroprotection in CNS inflammatory disease. J. Neurol. Sci. 2005, 233, 21-25.

10. Orgado, J.M.; Fernandez-Ruiz, J.; Romero, J. The endocannabinoid system in neuropathological states. Int. Rev. Psychiatry 2009, 21, 172-180.

11. Slatkin, N.E. Cannabinoids in the treatment of chemotherapy-induced nausea and vomiting: beyond prevention of acute emesis. J. Support. Oncol. 2007, 5, 1-19.

12. Lutge, E.E.; Gray, A.; Siegfried, N. The medical use of cannabis for reducing morbidity and mortality in patients with HIV/AIDS. Cochrane Database Syst. Rev. 2013, 4. Available online: http://onlinelibrary.wiley.com/doi/10.1002/14651858.CD005175.pub3/pdf/standard (accessed on 10 November 2014)

13. Sutton, I.R.; Daeninck, P. Cannabinoids in the management of intractable chemotherapy-induced nausea and vomiting and cancer-related pain. J. Support Oncol. 2006, 4, 531-535.

14. Vaney, C.; Heinzel-Gutenbrunner, M.; Jobin, P.; Tschopp, F.; Gattlen, B.; Hagen, U.; Schnelle, M.; Reif, M. Efficacy, safety and tolerability of an orally administered cannabis extract in the treatment of spasticity in patients with multiple sclerosis: A randomized, double-blind, placebo-controlled, crossover study. Mult. Scler. 2004, 10, 417-424.

15. Wilkinson, J.D.; Whalley, B.J.; Baker, D.; Pryce, G.; Constanti, A.; Gibbons, S.; Williamson, E.M. Medicinal cannabis: Is $\Delta^{9}$-tetrahydrocannabinol necessary for all its effects? J. Pharm. Pharmacol. 2003, 55, 1687-1694.

16. Brenneisen, R. Chemistry and analysis of phytocannabinoids and other Cannabis constituents.In Marijuana and the Cannabinoids; ElSohly, M.A., Ed.; Humana Press: Totowa, NJ, USA, 2007; pp. 17-49. 
17. Happyana, N.; Agnolet, S.; Muntendam, R.; van Dam, A.; Schneider, B.; Kayser, O. Analysis of cannabinoids in laser-microdissected trichomes of medicinal Cannabis sativa using LCMS and cryogenic NMR. Phytochemistry 2013, 87, 51-59.

18. De Zeeuw, R.A.; Wijsbeek, J.; Breimer, D.D.; Vree, T.B.; van Ginneken, C.A.; van Rossum, J.M. Cannabinoids with a propyl side chain in cannabis: Occurrence and chromatographic behavior. Science 1972, 175, 778-779.

19. De Meijer, E.P.; Bagatta, M.; Carboni, A.; Crucitti, P.; Moliterni, V.M.; Ranalli, P.; Mandolino, G. The inheritance of chemical phenotype in Cannabis sativa L. Genetics 2003, 163, 335-346.

20. Mandolino, G.; Carboni, A. Potential of marker assisted selection in hemp genetic improvement. Euphytica 2004, 140, 107-120.

21. Mahlberg, P.G.; Kim, E.S. Accumulation of cannabinoids in glandular trichomes of Cannabis (Cannabaceae). J. Ind. Hemp. 2004, 9, 15-36.

22. Basile, A. Understanding the Regulating Mechanisms behind Cannabinoid Biosynthesis. Ph.D. Thesis, Scuola Superiore Sant'Anna, Pisa, Italy, May 2014.

23. Pertwee, R.G. The diverse CB1 and CB2 receptor pharmacology of three plant cannabinoids: Delta9-tetrahydrocannabinol, cannabidiol and delta9-tetrahydrocannabivarin. Br. J. Pharmacol. 2008, 153, 199-215.

24. Morimoto, S.; Komatsu, K.; Taura, F.; Shoyama, Y. Purification and characterization of cannabichromenic acid synthase from Cannabis sativa. Phytochemistry 1998, 49, 1525-1529.

25. Shoyama, Y.; Tamada, T.; Kurihara, K.; Takeuchi, A.; Taura, F.; Arai, S.; Blaber, M.; Shoyama, Y.; Morimoto, S.; Kuroki, R. Structure and function of 1-tetrahydrocannabinolic acid (THCA) synthase, the enzyme controlling the psychoactivity of Cannabis sativa. J. Mol. Biol. 2012, 423, 96-105.

26. Shire, D.; Carillon, C.; Kaghad, M.; Calandra, B.; Rinaldi-Carmona, M.; le Fur, G.; Caput, D.; Ferrara, P. An amino-terminal variant of the central cannabinoid receptor resulting from alternative splicing. J. Biol. Chem.1995, 270, 3726-3731.

27. Ryberg, E.; Vu, H.K.; Larsson, N.; Groblewski, T.; Hjorth, S.; Elebring, T.; Sjogren, S.; Greasley, P.J. Identification and characterisation of a novel splice variant of the human $\mathrm{CB} 1$ receptor. FEBS Lett. 2005, 579, 259-264.

28. Matsuda, L.A.; Lolait, S.J.; Brownstein, M.J.; Young, A.C.; Bonner, T.I. Structure of a cannabinoid receptor and functional expression of the cloned cDNA. Nature 1990, 346, 561-564.

29. Biegon, A.; Kerman, I.A. Autoradiographic study of pre- and postnatal distribution of cannabinoid receptors in human brain. NeuroImage 2001, 14, 1463-1468.

30. Glass, M.; Dragunow, M.; Faull, R.L. Cannabinoid receptors in the human brain: A detailed anatomical and quantitative autoradiographic study in the fetal, neonatal and adult human brain. Neuroscience 1997, 77, 299-318.

31. Munro, S.; Thomas, K.L.; Abu-Shaar, M. Molecular characterization of a peripheral receptor for cannabinoids. Nature 1993, 365, 61-65.

32. Van Sickle, M.D.; Duncan, M.; Kingsley, P.J.; Mouihate, A.; Urbani, P.; Mackie, K.; Stella, N.; Makriyannis, A.; Piomelli, D.; Davison, J.S.; et al. Identification and functional characterization of brainstem cannabinoid CB2 receptors. Science 2005, 310, 329-332. 
33. Maresz, K.; Carrier, E.J.; Ponomarev, E.D.; Hillard, C.J.; Dittel, B.N. Modulation of the cannabinoid CB2 receptor in microglial cells in response to inflammatory stimuli. J. Neurochem. 2005, 95, 437-445.

34. Ashton, J.C.; Rahman, R.M.; Nair, S.M.; Sutherland, B.A.; Glass, M.; Appleton, I. Cerebral hypoxia-ischemia and middle cerebral artery occlusion induce expression of the cannabinoid CB2 receptor in the brain. Neurosci. Lett. 2007, 412, 114-117.

35. Pertwee, R.G.; Ross, R.A. Cannabinoid receptors and their ligands. Prostaglandins Leukot. Essent. Fatty Acids 2002, 66, 101-121.

36. Maccarrone, M.; Finazzi-Agro, A. Endocannabinoids and their actions. Vitam. Horm. 2002, 65, 225-255.

37. Mackie, K.; Devane, W.A.; Hille, B. Anandamide, an endogenous cannabinoid, inhibits calcium currents as a partial agonist in N18 neuroblastoma cells. Mol. Pharmacol. 1993, 44, 498-503.

38. Buckley, N.E. The peripheral cannabinoid receptor knockout mice: An update. Br. J. Pharmacol. 2008, 153, 309-318.

39. Valverde, O.; Karsak, M.; Zimmer, A. Analysis of the endocannabinoid system by using CB1 cannabinoid receptor knockout mice. Handb. Exp. Pharmacol. 2005, 117-145.

40. Chuang, H.H.; Prescott, E.D.; Kong, H.; Shields, S.; Jordt, S.E.; Basbaum, A.I.; Chao, M.V.; Julius, D. Bradykinin and nerve growth factor release the capsaicin receptor from PtdIns(4,5)P2-mediated inhibition. Nature 2001, 411, 957-962.

41. Caterina, M.J.; Leffler, A.; Malmberg, A.B.; Martin, W.J.; Trafton, J.; Petersen-Zeitz, K.R.; Koltzenburg, M.; Basbaum, A.I.; Julius, D. Impaired nociception and pain sensation in mice lacking the capsaicin receptor. Science 2000, 288, 306-313.

42. Cristino, L.; de Petrocellis, L.; Pryce, G.; Baker, D.; Guglielmotti, V.; di Marzo, V. Immunohistochemical localization of cannabinoid type 1 and vanilloid transient receptor potential vanilloid type 1 receptors in the mouse brain. Neuroscience 2006, 139, 1405-1415.

43. Mezey, E.; Toth, Z.E.; Cortright, D.N.; Arzubi, M.K.; Krause, J.E.; Elde, R.; Guo, A.; Blumberg, P.M.; Szallasi, A. Distribution of mRNA for vanilloid receptor subtype 1 (VR1), and VR1-like immunoreactivity, in the central nervous system of the rat and human. Proc. Natl. Acad. Sci. USA 2000, 97, 3655-3660.

44. Brown, A.J. Novel cannabinoid receptors. Br. J. Pharmacol. 2007, 152, 567-575.

45. Pertwee, R.G.; Howlett, A.C.; Abood, M.E.; Alexander, S.P.; di Marzo, V.; Elphick, M.R.; Greasley, P.J.; Hansen, H.S.; Kunos, G.; Mackie, K.; et al. International Union of Basic and Clinical Pharmacology. LXXIX. Cannabinoid receptors and their ligands: Beyond $\mathrm{CB}(1)$ and CB(2). Pharmacol. Rev. 2010, 62, 588-631.

46. Ryberg, E.; Larsson, N.; Sjogren, S.; Hjorth, S.; Hermansson, N.O.; Leonova, J.; Elebring, T.; Nilsson, K.; Drmota, T.; Greasley, P.J. The orphan receptor GPR55 is a novel cannabinoid receptor. Br. J. Pharmacol. 2007, 152, 1092-1101.

47. Baker, D.; Pryce, G.; Davies, W.L.; Hiley, C.R. In silico patent searching reveals a new cannabinoid receptor. Trends Pharmacol. Sci. 2006, 27, 1-4.

48. Henstridge, C.M.; Balenga, N.A.; Schroder, R.; Kargl, J.K.; Platzer, W.; Martini, L.; Arthur, S.; Penman, J.; Whistler, J.L.; Kostenis, E.; et al. GPR55 ligands promote receptor coupling to multiple signalling pathways. Br. J. Pharmacol. 2010, 160, 604-614. 
49. Oka, S.; Kimura, S.; Toshida, T.; Ota, R.; Yamashita, A.; Sugiura, T. Lysophosphatidylinositol induces rapid phosphorylation of $\mathrm{p} 38$ mitogen-activated protein kinase and activating transcription factor 2 in HEK293 cells expressing GPR55 and IM-9 lymphoblastoid cells. J. Biochem. 2010, 147, 671-678.

50. Buhl, A.M.; Johnson, N.L.; Dhanasekaran, N.; Johnson, G.L. G alpha 12 and G alpha 13 stimulate Rho-dependent stress fiber formation and focal adhesion assembly. J. Biol. Chem. 1995, 270, 24631-24634.

51. McHugh, D.; Hu, S.S.; Rimmerman, N.; Juknat, A.; Vogel, Z.; Walker, J.M.; Bradshaw, H.B. $\mathrm{N}$-arachidonoyl glycine, an abundant endogenous lipid, potently drives directed cellular migration through GPR18, the putative abnormal cannabidiol receptor. BMC Neurosci. 2010, 11, doi:10.1186/1471-2202-11-44.

52. Gantz, I.; Muraoka, A.; Yang, Y.K.; Samuelson, L.C.; Zimmerman, E.M.; Cook, H.; Yamada, T. Cloning and chromosomal localization of a gene (GPR18) encoding a novel seven transmembrane receptor highly expressed in spleen and testis. Genomics 1997, 42, 462-466.

53. Fredriksson, R.; Hoglund, P.J.; Gloriam, D.E.; Lagerstrom, M.C.; Schioth, H.B. Seven evolutionarily conserved human rhodopsin G protein-coupled receptors lacking close relatives. FEBS Lett. 2003, 554, 381-388.

54. Overton, H.A.; Babbs, A.J.; Doel, S.M.; Fyfe, M.C.; Gardner, L.S.; Griffin, G.; Jackson, H.C.; Procter, M.J.; Rasamison, C.M.; Tang-Christensen, M.; et al. Deorphanization of a G protein-coupled receptor for oleoylethanolamide and its use in the discovery of small-molecule hypophagic agents. Cell Metab. 2006, 3, 167-175.

55. Barnes, N.M.; Sharp, T. A review of central 5-HT receptors and their function. Neuropharmacology 1999, 38, 1083-1152.

56. Sprouse, J.S.; Aghajanian, G.K. (-)-Propranolol blocks the inhibition of serotonergic dorsal raphe cell firing by 5-HT1A selective agonists. Eur. J. Pharmacol. 1986, 128, 295-298.

57. Araneda, R.; Andrade, R. 5-Hydroxytryptamine2 and 5-hydroxytryptamine 1A receptors mediate opposing responses on membrane excitability in rat association cortex. Neuroscience 1991, 40, 399-412.

58. Pacher, P.; Batkai, S.; Kunos, G. The endocannabinoid system as an emerging target of pharmacotherapy. Pharmacol. Rev. 2006, 58, 389-462.

59. Campos, A.C.; Moreira, F.A.; Gomes, F.V.; del Bel, E.A.; Guimaraes, F.S. Multiple mechanisms involved in the large-spectrum therapeutic potential of cannabidiol in psychiatric disorders. Philos. Trans R. Soc. Lond. B Biol. Sci. 2012, 367, 3364-3378.

60. Kunos, G.; Osei-Hyiaman, D.; Batkai, S.; Sharkey, K.A.; Makriyannis, A. Should peripheral CB(1) cannabinoid receptors be selectively targeted for therapeutic gain? Trends Pharmacol. Sci. 2009, $30,1-7$.

61. Izzo, A.A.; Borrelli, F.; Capasso, R.; di Marzo, V.; Mechoulam, R. Non-psychotropic plant cannabinoids: New therapeutic opportunities from an ancient herb. Trends Pharmacol. Sci. 2009, 30, 515-527.

62. Jean-Gilles, L.; Gran, B.; Constantinescu, C.S. Interaction between cytokines, cannabinoids and the nervous system. Immunobiology 2010, 215, 606-610. 
63. Esposito, G.; de Filippis, D.; Maiuri, M.C.; de Stefano, D.; Carnuccio, R.; Iuvone, T. Cannabidiol inhibits inducible nitric oxide synthase protein expression and nitric oxide production in beta-amyloid stimulated PC12 neurons through p38 MAP kinase and NF- $\kappa$ B involvement. Neurosci. Lett. 2006, 399, 91-95.

64. Rajesh, M.; Mukhopadhyay, P.; Batkai, S.; Hasko, G.; Liaudet, L.; Drel, V.R.; Obrosova, I.G.; Pacher, P. Cannabidiol attenuates high glucose-induced endothelial cell inflammatory response and barrier disruption. Am. J. Physiol. Heart Circ. Physiol. 2007, 293, H610-H619.

65. Fagan, S.G.; Campbell, V.A. The influence of cannabinoids on generic traits of neurodegeneration. Br. J. Pharmacol. 2014, 171, 1347-1360.

66. Alexander, G.E. Biology of Parkinson's disease: Pathogenesis and pathophysiology of a multisystem neurodegenerative disorder. Dialog. Clin. Neurosci. 2004, 6, 259-280.

67. Tabrez, S.; Jabir, N.R.; Shakil, S.; Greig, N.H.; Alam, Q.; Abuzenadah, A.M.; Damanhouri, G.A.; Kamal, M.A. A synopsis on the role of tyrosine hydroxylase in Parkinson's disease. CNS Neurol. Disord. Drug Targets 2012, 11, 395-409.

68. Adams, J.D., Jr.; Chang, M.L.; Klaidman, L. Parkinson's disease-Redox mechanisms. Curr. Med. Chem. 2001, 8, 809-814.

69. Brotchie, J.M. CB1 cannabinoid receptor signalling in Parkinson's disease. Curr. Opin. Pharmacol. 2003, 3, 54-61.

70. Gubellini, P.; Picconi, B.; Bari, M.; Battista, N.; Calabresi, P.; Centonze, D.; Bernardi, G.; Finazzi-Agro, A.; Maccarrone, M. Experimental parkinsonism alters endocannabinoid degradation: Implications for striatal glutamatergic transmission. J. Neurosci. 2002, 22, 6900-6907.

71. Pisani, A.; Fezza, F.; Galati, S.; Battista, N.; Napolitano, S.; Finazzi-Agro, A.; Bernardi, G.; Brusa, L.; Pierantozzi, M.; Stanzione, P.; Maccarrone, M. High endogenous cannabinoid levels in the cerebrospinal fluid of untreated Parkinson's disease patients. Ann. Neurol. 2005, 57, 777-779.

72. Pisani, V.; Moschella, V.; Bari, M.; Fezza, F.; Galati, S.; Bernardi, G.; Stanzione, P.; Pisani, A.; Maccarrone, M. Dynamic changes of anandamide in the cerebrospinal fluid of Parkinson's disease patients. Mov. Disord. 2010, 25, 920-924.

73. Hurley, M.J.; Mash, D.C.; Jenner, P. Expression of cannabinoid CB1 receptor mRNA in basal ganglia of normal and parkinsonian human brain. J. Neural. Transm. 2003, 110, 1279-1288.

74. Pisani, V.; Madeo, G.; Tassone, A.; Sciamanna, G.; Maccarrone, M.; Stanzione, P.; Pisani, A. Homeostatic changes of the endocannabinoid system in Parkinson's disease. Mov. Disord. 2011, 26, 216-222.

75. Buchanan, R.J.; Darrow, D.P.; Meier, K.T.; Robinson, J.; Schiehser, D.M.; Glahn, D.C.; Nadasdy, Z. Changes in GABA and glutamate concentrations during memory tasks in patients with Parkinson's disease undergoing DBS surgery. Front. Hum. Neurosci. 2014, 8, doi:10.3389/fnhum.2014.00081.

76. David, H.N. Towards a reconceptualization of striatal interactions between glutamatergic and dopaminergic neurotransmission and their contribution to the production of movements. Curr. Neuropharm. 2009, 7, 132-141.

77. Johnson, K.A.; Conn, P.J.; Niswender, C.M. Glutamate receptors as therapeutic targets for Parkinson's disease. CNS Neurol. Disord. Drug Targets 2009, 8, 475-491.

78. Koutsilieri, E.; Riederer, P. Excitotoxicity and new antiglutamatergic strategies in Parkinson's disease and Alzheimer's disease. Parkinsonism Relat. Disord. 2007, 13, S329-S331. 
79. Marjama-Lyons, J.; Koller, W. Tremor-predominant Parkinson's disease. Approaches to treatment. Drugs Aging 2000, 16, 273-278.

80. Maneuf, Y.P.; Crossman, A.R.; Brotchie, J.M. The cannabinoid receptor agonist WIN 55,212-2 reduces D2, but not D1, dopamine receptor-mediated alleviation of akinesia in the reserpine-treated rat model of Parkinson's disease. Exp. Neurol.1997, 148, 265-270.

81. Lastres-Becker, I.; Molina-Holgado, F.; Ramos, J.A.; Mechoulam, R.; Fernandez-Ruiz, J. Cannabinoids provide neuroprotection against 6-hydroxydopamine toxicity in vivo and in vitro: Relevance to Parkinson's disease. Neurobiol. Dis. 2005, 19, 96-107.

82. Fernandez-Ruiz, J.; Moreno-Martet, M.; Rodriguez-Cueto, C.; Palomo-Garo, C.; Gomez-Canas, M.; Valdeolivas, S.; Guaza, C.; Romero, J.; Guzman, M.; Mechoulam, R.; et al. Prospects for cannabinoid therapies in basal ganglia disorders. Br. J. Pharmacol. 2011, 163, 1365-1378.

83. Garcia-Arencibia, M.; Garcia, C.; Fernandez-Ruiz, J. Cannabinoids and Parkinson's disease. CNS Neurol. Disord. Drug Targets 2009, 8, 432-439.

84. Garcia, C.; Palomo-Garo, C.; Garcia-Arencibia, M.; Ramos, J.; Pertwee, R.; Fernandez-Ruiz, J. Symptom-relieving and neuroprotective effects of the phytocannabinoid $\Delta 9-\mathrm{THCV}$ in animal models of Parkinson's disease. Br. J. Pharmacol 2011, 163, 1495-1506.

85. Consroe, P. Brain cannabinoid systems as targets for the therapy of neurological disorders. Neurobiol Dis. 1998, 5, 534-551.

86. Muller-Vahl, K.R.; Kolbe, H.; Schneider, U.; Emrich, H.M. Cannabis in movement disorders. Forsch Komplement. 1999, 6, 23-27.

87. Brotchie, J.M. Adjuncts to dopamine replacement: A pragmatic approach to reducing the problem of dyskinesia in Parkinson's disease. Mov. Disord. 1998, 13, 871-876.

88. Meschler, J.P.; ConleyT.J.; Howlett, A.C. Cannabinoid and dopamine interaction in rodent brain: Effects on locomotor activity. Pharmacol. Biochem. Behav. 2000, 67, 567-573.

89. Sieradzan, K.A.; Fox, S.H.; Hill, M.; Dick, J.P.; Crossman, A.R.; Brotchie, J.M. Cannabinoids reduce levodopa-induced dyskinesia in Parkinson's disease: A pilot study. Neurology 2001, 57, 2108-2111.

90. Carroll, C.B.; Bain, P.G.; Teare, L.; Liu, X.; Joint, C.; Wroath, C.; Parkin, S.G.; Fox, P.; Wright, D.; Hobart, J.; et al. Cannabis for dyskinesia in Parkinson disease: A randomized double-blind crossover study. Neurology 2004, 63, 1245-1250.

91. MacDonald, M.E.; Ambrose, C.M.; Duyao, M.P.; Myers, R.H.; Lin, C.; Srinidhi, L.; Barnes, G.; Taylor, S.A.; James, M.; Groot, N. A novel gene containing a trinucleotide repeat that is expanded and unstable on Huntington's disease chromosomes. Cell 1993, 72, 971-983.

92. Zuccato, C.; Valenza, M.; Cattaneo, E. Molecular mechanisms and potential therapeutical targets in Huntington's disease. Physiol. Rev. 2010, 90, 905-981.

93. Francelle, L.; Galvan, L.; Brouillet, E. Possible involvement of self-defense mechanisms in the preferential vulnerability of the striatum in Huntington's disease. Front. Cell Neurosci. 2014, 8, doi:10.3389/fncel.2014.00295.

94. Kumar, P.; Kalonia, H.; Kumar, A. Huntington's disease: Pathogenesis to animal models. Pharmacol. Rep. 2010, 62, 1-14. 
95. Swerdlow, N.R.; Paulsen, J.; Braff, D.L.; Butters, N.; Geyer, M.A.; Swenson, M.R. Impaired prepulse inhibition of acoustic and tactile startle response in patients with Huntington's disease. J. Neurol. Neurosurg. Psychiatry 1995, 58, 192-200.

96. Sagredo, O.; Pazos, M.R.; Valdeolivas, S.; Fernandez-Ruiz, J. Cannabinoids: Novel medicines for the treatment of Huntington's disease. Recent Pat. CNS Drug. Discov. 2012, 7, 41-48.

97. Ross, C.A.; Tabrizi, S.J. Huntington's disease: From molecular pathogenesis to clinical treatment. Lancet Neurol. 2011, 10, 83-98.

98. Groves, P.M. A theory of the functional organization of the neostriatum and the neostriatal control of voluntary movement. Brain Res. 1983, 286, 9-32.

99. Penney, J.B., Jr.; Young, A.B. Speculations on the functional anatomy of basal ganglia disorders. Annu. Rev. Neurosci. 1983, 6, 73-94.

100. Palazuelos, J.; Aguado, T.; Pazos, M.R.; Julien, B.; Carrasco, C.; Resel, E.; Sagredo, O.; Benito, C.; Romero, J.; Azcoitia, I.; et al. Microglial CB2 cannabinoid receptors are neuroprotective in Huntington's disease excitotoxicity. Brain 2009, 132, 3152-3164.

101. Sagredo, O.; Gonzalez, S.; Aroyo, I.; Pazos, M.R.; Benito, C.; Lastres-Becker, I.; Romero, J.P.; Tolon, R.M.; Mechoulam, R.; Brouillet, E.; et al. Cannabinoid CB2 receptor agonists protect the striatum against malonate toxicity: Relevance for Huntington's disease. Glia 2009, 57, 1154-1167.

102. Chiarlone, A.; Bellocchio, L.; Blazquez, C.; Resel, E.; Soria-Gomez, E.; Cannich, A.; Ferrero, J.J.; Sagredo, O.; Benito, C.; Romero, J.; et al. A restricted population of CB1 cannabinoid receptors with neuroprotective activity. Proc. Natl. Acad. Sci. USA 2014, 111, 8257-8262.

103. Mangiarini, L.; Sathasivam, K.; Seller, M.; Cozens, B.; Harper, A.; Hetherington, C.; Lawton, M.; Trottier, Y.; Lehrach, H.; Davies, S.W.; et al. Exon 1 of the HD gene with an expanded CAG repeat is sufficient to cause a progressive neurological phenotype in transgenic mice. Cell 1996, 87, 493-506.

104. Valdeolivas, S.; Navarrete, C.; Cantarero, I.; Bellido, M.L.; Munoz, E.; Sagredo, O. Neuroprotective Properties of Cannabigerol in Huntington's Disease: Studies in R6/2 Mice and 3-Nitropropionate-lesioned Mice. Neurotherapeutics 2014, 1-14, doi:10.1007/s13311-014-0304-z.

105. Valdeolivas, S.; Satta, V.; Pertwee, R.G.; Fernandez-Ruiz, J.; Sagredo, O. Sativex-like combination of phytocannabinoids is neuroprotective in malonate-lesioned rats, an inflammatory model of Huntington's disease: Role of CB1 and CB2 receptors. ACS Chem. Neurosci. 2012, 3, 400-406.

106. Sagredo, O.; Pazos, M.R.; Satta, V.; Ramos, J.A.; Pertwee, R.G.; Fernandez-Ruiz, J. Neuroprotective effects of phytocannabinoid-based medicines in experimental models of Huntington's disease. $J$. Neurosci. Res. 2011, 89, 1509-1518.

107. Fernandez-Ruiz, J.; Romero, J.; Velasco, G.; Tolon, R.M.; Ramos, J.A.; Guzman, M. Cannabinoid CB2 receptor: A new target for controlling neural cell survival? Trends Pharmacol. Sci. 2007, 28, 39-45.

108. Scotter, E.L.; Goodfellow, C.E.; Graham, E.S.; Dragunow, M.; Glass, M. Neuroprotective potential of CB1 receptor agonists in an in vitro model of Huntington's disease. Br. J. Pharmacol. 2010, 160, 747-761.

109. Consroe, P.; Laguna, J.; Allender, J.; Snider, S.; Stern, L.; Sandyk, R.; Kennedy, K.; Schram, K. Controlled clinical trial of cannabidiol in Huntington's disease. Pharmacol. Biochem. Behav. 1991, 40, 701-708. 
110. Curtis, A.; Rickards, H. Nabilone could treat chorea and irritability in Huntington's disease. J. Neuropsychiatry Clin. Neurosci. 2006, 18, 553-554.

111. Muller-Vahl, K.R.; Schneider, U.; Emrich, H.M. Nabilone increases choreatic movements in Huntington's disease. Mov. Disord. 1999, 14, 1038-1040.

112. Curtis, A.; Mitchell, I.; Patel, S.; Ives, N.; Rickards, H. A pilot study using nabilone for symptomatic treatment in Huntington's disease. Mov. Disord. 2009, 24, 2254-2259.

113. Barnes, D.E.; Yaffe, K. The projected effect of risk factor reduction on Alzheimer's disease prevalence. Lancet Neurol. 2011, 10, 819-828.

114. Walsh, D.M.; Selkoe, D.J. A beta oligomers-A decade of discovery. J. Neurochem. 2007, 101, 1172-1184.

115. Mi, K.; Johnson, G.V. The role of tau phosphorylation in the pathogenesis of Alzheimer's disease. Curr. Alzheimer Res. 2006, 3, 449-463.

116. Benito, C.; Tolon, R.M.; Pazos, M.R.; Nunez, E.; Castillo, A.I.; Romero, J. Cannabinoid CB2 receptors in human brain inflammation. Br. J. Pharmacol. 2008, 153, 277-285.

117. Eubanks, L.M.; Rogers, C.J.; Beuscher, A.E., IV; Koob, G.F.; Olson, A.J.; Dickerson, T.J.; Janda, K. A molecular link between the active component of marijuana and Alzheimer's disease pathology. Mol. Pharm. 2006, 3, 773-777.

118. Iuvone, T.; Esposito, G.; Esposito, R.; Santamaria, R.; di Rosa, M.; Izzo, A.A. Neuroprotective effect of cannabidiol, a non-psychoactive component from Cannabis sativa, on beta-amyloid-induced toxicity in PC12 cells. J. Neurochem. 2004, 89, 134-141.

119. Esposito, G.; Scuderi, C.; Savani, C.; Steardo, L., Jr.; de Filippis, D.; Cottone, P.; Iuvone, T.; Cuomo, V.; Steardo, L. Cannabidiol in vivo blunts beta-amyloid induced neuroinflammation by suppressing IL-1 $\beta$ and iNOS expression. Br. J. Pharmacol. 2007, 151, 1272-1279.

120. Martin-Moreno, A.M.; Reigada, D.; Ramirez, B.G.; Mechoulam, R.; Innamorato, N.; Cuadrado, A.; de Ceballos, M.L. Cannabidiol and other cannabinoids reduce microglial activation in vitro and in vivo: Relevance to Alzheimer's disease. Mol. Pharm. 2011, 79, 964-973.

121. Scuderi, C.; Steardo, L.; Esposito, G. Cannabidiol promotes amyloid precursor protein ubiquitination and reduction of beta amyloid expression in SHSY5YAPP+ cells through PPARgamma involvement. Phytother. Res. 2014, 28, 1007-1013.

122. Aso, E.; Sanchez-Pla, A.; Vegas-Lozano, E.; Maldonado, R.; Ferrer, I. Cannabis-Based Medicine Reduces Multiple Pathological Processes in AbetaPP/PS1 Mice. J. Alzheimers Dis. 2014. Available online: http://scibite.com/site/library/2014_8/1/0/25125475.html (accessed on 10 November 2014).

123. Walther, S.; Mahlberg, R.; Eichmann, U.; Kunz, D. $\Delta 9$-tetrahydrocannabinol for nighttime agitation in severe dementia. Psychopharmacology 2006, 185, 524-528.

124. Siffrin, V.; Brandt, A.U.; Herz, J.; Zipp, F. New insights into adaptive immunity in chronic neuroinflammation. Adv. Immunol. 2007, 96, 1-40.

125. Pryce, G.; Baker, D. Control of spasticity in a multiple sclerosis model is mediated by CB1, not CB2, cannabinoid receptors. Br. J. Pharmacol. 2007, 150, 519-525.

126. Lyman, W.D.; Sonett, J.R.; Brosnan, C.F.; Elkin, R.; Bornstein, M.B. Delta 9-tetrahydrocannabinol: A novel treatment for experimental autoimmune encephalomyelitis. J. Neuroimmunol. 1989, 23, 73-81. 
127. Molina-Holgado, E.; Vela, J.M.; Arevalo-Martin, A.; Almazan, G.; Molina-Holgado, F.; Borrell, J.; Guaza, C. Cannabinoids promote oligodendrocyte progenitor survival: Involvement of cannabinoid receptors and phosphatidylinositol-3 kinase/Akt signaling. J. Neurosci. 2002, 22, 9742-9753.

128. Cabral, G.A.; Harmon, K.N.; Carlisle, S.J. Cannabinoid-mediated inhibition of inducible nitric oxide production by rat microglial cells: Evidence for CB1 receptor participation. Adv. Exp. Med. Biol. 2001, 493, 207-214.

129. Klein, T.W.; Lane, B.; Newton, C.A.; Friedman, H. The cannabinoid system and cytokine network. Proc. Soc. Exp. Biol. Med. 2000, 225, 1-8.

130. Arevalo-Martin, A.; Vela, J.M.; Molina-Holgado, E.; Borrell, J.; Guaza, C. Therapeutic action of cannabinoids in a murine model of multiple sclerosis. J. Neurosci. 2003, 23, 2511-2516.

131. Ribeiro, R.; Yu, F.; Wen, J.; Vana, A.; Zhang, Y. Therapeutic potential of a novel cannabinoid agent CB52 in the mouse model of experimental autoimmune encephalomyelitis. Neuroscience 2013, 254, 427-442.

132. Cabranes, A.;Venderova, K.; de Lago, E.; Fezza, F.; Sanchez, A.; Mestre, L.; Valenti, M.; Garcia-Merino, A.; Ramos, J.A.; di Marzo, V.; et al. Decreased endocannabinoid levels in the brain and beneficial effects of agents activating cannabinoid and/or vanilloid receptors in a rat model of multiple sclerosis. Neurobiol. Dis. 2005, 20, 207-217.

133. Cabranes, A.; Pryce, G.; Baker, D.; Fernandez-Ruiz, J. Changes in CB1 receptors in motor-related brain structures of chronic relapsing experimental allergic encephalomyelitis mice. Brain Res. 2006, 1107, 199-205.

134. Baker, D.; Pryce, G.; Croxford, J.L.; Brown, P.; Pertwee, R.G.; Huffman, J.W.; Layward, L. Cannabinoids control spasticity and tremor in a multiple sclerosis model. Nature 2000, 404, 84-87.

135. Buccellato, E.; Carretta, D.; Utan, A.; Cavina, C.; Speroni, E.; Grassi, G.; Candeletti, S.; Romualdi, P. Acute and chronic cannabinoid extracts administration affects motor function in a CREAE model of multiple sclerosis. J. Ethnopharmacol. 2011, 133, 1033-1038.

136. Bahr, B.A.; Karanian, D.A.; Makanji, S.S.; Makriyannis, A. Targeting the endocannabinoid system in treating brain disorders. Expert Opin. Investig. Drugs 2006, 15, 351-365.

137. Centonze, D.; Bari, M.; Rossi, S.; Prosperetti, C.; Furlan, R.; Fezza, F.; de Chiara, V.; Battistini, L.; Bernardi, G.; Bernardini, S.; et al. The endocannabinoid system is dysregulated in multiple sclerosis and in experimental autoimmune encephalomyelitis. Brain 2007, 130, 2543-2553.

138. Jean-Gilles, L.; Feng, S.; Tench, C.R.; Chapman, V.; Kendall, D.A.; Barrett, D.A.; Constantinescu, C.S. Plasma endocannabinoid levels in multiple sclerosis. J. Neurol. Sci. 2009, 287, 212-215.

139. Nielsen, J.B.; Crone, C.; Hultborn, H. The spinal pathophysiology of spasticity-From a basic science point of view. Acta Physiol. 2007, 189, 171-180.

140. Paisley, S.; Beard, S.; Hunn, A.; Wight, J. Clinical effectiveness of oral treatments for spasticity in multiple sclerosis: A systematic review. Mult. Scler. 2002, 8, 319-329.

141. Zajicek, J.; Fox, P.; Sanders, H.; Wright, D.; Vickery, J.; Nunn, A.; Thompson, A.; Group, U.M.R. Cannabinoids for treatment of spasticity and other symptoms related to multiple sclerosis (CAMS study): Multicentre randomised placebo-controlled trial. Lancet 2003, 362, 1517-1526.

142. Zajicek, J.P.; Sanders, H.P.; Wright, D.E.; Vickery, P.J.; Ingram, W.M.; Reilly, S.M.; Nunn, A.J.; Teare, L.J.; Fox, P.J.; Thompson, A.J. Cannabinoids in multiple sclerosis (CAMS) study: Safety and efficacy data for 12 months follow up. J. Neurol. Neurosurg. Psychiatry 2005, 76, 1664-1669. 
143. Zajicek, J.; Ball, S.; Wright, D.; Vickery, J.; Nunn, A.; Miller, D.; Gomez Cano, M.; McManus, D.; Mallik, S.; Hobart, J. Cupid investigator group. Effect of dronabinol on progression in progressive multiple sclerosis (CUPID): A randomised, placebo-controlled trial. Lancet Neurol. 2013, 12, $857-865$.

144. Turcotte, D.; Doupe, M.; Torabi, M.; Gomori, A.; Ethans, K.; Esfahani, F.; Galloway, K.; Namaka, M. Nabilone as an Adjunctive to Gabapentin for Multiple Sclerosis-Induced Neuropathic Pain: A Randomized Controlled Trial. Pain Med. 2014, doi:10.1111/pme.12569.

145. Freeman, R.M.; Adekanmi, O.; Waterfield, M.R.; Waterfield, A.E.; Wright, D.; Zajicek, J. The effect of cannabis on urge incontinence in patients with multiple sclerosis: A multicentre, randomised placebo-controlled trial (CAMS-LUTS). Int. Urogynecol. J. Pelvic Floor Dysfunct. 2006, 17, 636-641.

146. Nicholson, S.J.; Witherden, A.S.; Hafezparast, M.; Martin, J.E.; Fisher, E.M. Mice, the motor system, and human motor neuron pathology. Mamm. Genome 2000, 11, 1041-1052.

147. Ludolph, A.C.; Meyer, T.; Riepe, M.W. The role of excitotoxicity in ALS-What is the evidence? J. Neurol. 2000, 247, I7-I16.

148. Robberecht, W. Oxidative stress in amyotrophic lateral sclerosis. J. Neurol. 2000, 247, I1-I6.

149. Raman, C.; McAllister, S.D.; Rizvi, G.; Patel, S.G.; Moore, D.H.; Abood, M.E. Amyotrophic lateral sclerosis: Delayed disease progression in mice by treatment with a cannabinoid. Amyotroph. Lateral Scler. Other Motor Neuron. Disord. 2004, 5, 33-39.

150. Bilsland, L.G.; Dick, J.R.; Pryce, G.; Petrosino, S.; di Marzo, V.; Baker, D.; Greensmith, L. Increasing cannabinoid levels by pharmacological and genetic manipulation delay disease progression in SOD1 mice. FASEB J. 2006, 20, 1003-1005.

151. Weydt, P.; Hong, S.; Witting, A.; Moller, T.; Stella, N.; Kliot, M. Cannabinol delays symptom onset in SOD1 (G93A) transgenic mice without affecting survival. Amyotroph. Lateral Scler. Other Motor Neuron. Disord. 2005, 6, 182-184.

152. Ramirez, B.G.; Blazquez, C.; Gomez del Pulgar, T.; Guzman, M.; de Ceballos, M.L. Prevention of Alzheimer's disease pathology by cannabinoids: Neuroprotection mediated by blockade of microglial activation. J. Neurosci. 2005, 25, 1904-1913.

153. Kim, K.; Moore, D.H.; Makriyannis, A.; Abood, M.E. AM1241, a cannabinoid CB2 receptor selective compound, delays disease progression in a mouse model of amyotrophic lateral sclerosis. Eur. J. Pharmacol. 2006, 542, 100-105.

154. Moreno-Martet, M.; Espejo-Porras, F.; Fernandez-Ruiz, J.; de Lago, E. Changes in endocannabinoid receptors and enzymes in the spinal cord of SOD1(G93A) transgenic mice and evaluation of a Sativex $((\mathrm{R}))$-like combination of phytocannabinoids: Interest for future therapies in amyotrophic lateral sclerosis. CNS Neurosci. Ther. 2014, 20, 809-815.

155. Yiangou, Y.; Facer, P.; Durrenberger, P.; Chessell, I.P.; Naylor, A.; Bountra, C.; Banati, R.R.; Anand, P. COX-2, CB2 and P2X7-immunoreactivities are increased in activated microglial cells/macrophages of multiple sclerosis and amyotrophic lateral sclerosis spinal cord. BMC Neurol. 2006, 6, doi:10.1186/1471-2377-6-12. 
156. Carter, G.T.; Rosen, B.S. Marijuana in the management of amyotrophic lateral sclerosis. Am. J. Hosp. Palliat. Care 2001, 18, 264-270.

157. Amtmann, D.; Weydt, P.; Johnson, K.L.; Jensen, M.P.; Carter, G.T. Survey of cannabis use in patients with amyotrophic lateral sclerosis. Am. J. Hosp. Palliat. Care 2004, 21, 95-104.

158. Brouns, R.; de Deyn, P.P. The complexity of neurobiological processes in acute ischemic stroke. Clin. Neurol. Neurosurg. 2009, 111, 483-495.

159. Sahota, P.; Savitz, S.I. Investigational therapies for ischemic stroke: Neuroprotection and neurorecovery. Neurotherapeutics 2011, 8, 434-451.

160. Jin, R.; Yang, G.; Li, G. Inflammatory mechanisms in ischemic stroke: Role of inflammatory cells. J. Leukoc. Biol. 2010, 87, 779-789.

161. Velayudhan, L.; van Diepen, E.; Marudkar, M.; Hands, O.; Suribhatla, S.; Prettyman, R.; Murray, J.; Baillon, S.; Bhattacharyya, S. Therapeutic potential of cannabinoids in neurodegenerative disorders: A selective review. Curr. Pharm. Des. 2014, 20, 2218-2230.

162. Alvarez, F.J.; Lafuente, H.; Rey-Santano, M.C.; Mielgo, V.E.; Gastiasoro, E.; Rueda, M.; Pertwee, R.G.; Castillo, A.I.; Romero, J.; Martinez-Orgado, J. Neuroprotective effects of the nonpsychoactive cannabinoid cannabidiol in hypoxic-ischemic newborn piglets. Pediatr. Res. 2008, 64, 653-658.

163. Mishima, K.; Hayakawa, K.; Abe, K.; Ikeda, T.; Egashira, N.; Iwasaki, K.; Fujiwara, M. Cannabidiol prevents cerebral infarction via a serotonergic 5-hydroxytryptamine1A receptor-dependent mechanism. Stroke 2005, 36, 1077-1082.

164. Maas, A.I.; Murray, G.; Henney, H., III; Kassem, N.; Legrand, V.; Mangelus, M.; Muizelaar, J.P.; Stocchetti, N.; Knoller, N.; Pharmos, T.B.I.I. Efficacy and safety of dexanabinol in severe traumatic brain injury: Results of a phase III randomised, placebo-controlled, clinical trial. Lancet Neurol. 2006, 5, 38-45.

165. Ferriero, D.M. Neonatal brain injury. N. Engl. J. Med. 2004, 351, 1985-1995.

166. Pazos, M.R.; Cinquina, V.; Gomez, A.; Layunta, R.; Santos, M.; Fernandez-Ruiz, J.; Martinez-Orgado, J. Cannabidiol administration after hypoxia-ischemia to newborn rats reduces long-term brain injury and restores neurobehavioral function. Neuropharmacology 2012, 63, 776-783.

167. Castillo, A.; Tolon, M.R.; Fernandez-Ruiz, J.; Romero, J.; Martinez-Orgado, J. The neuroprotective effect of cannabidiol in an in vitro model of newborn hypoxic-ischemic brain damage in mice is mediated by $\mathrm{CB}(2)$ and adenosine receptors. Neurobiol. Dis. 2010, 37, 434-440.

168. Pazos, M.R.; Mohammed, N.; Lafuente, H.; Santos, M.; Martinez-Pinilla, E.; Moreno, E.; Valdizan, E.; Romero, J.; Pazos, A.; Franco, R.; et al. Mechanisms of cannabidiol neuroprotection in hypoxic-ischemic newborn pigs: Role of 5HT(1A) and CB2 receptors. Neuropharmacology 2013, 71, 282-291.

169. Chang, B.S.; Lowenstein, D.H. Epilepsy. N. Engl. J. Med. 2003, 349, 1257-1266.

170. Kwan, P.; Brodie, M.J. Emerging drugs for epilepsy. Expert Opin. Emerg. Drugs 2007, 12, 407-422.

171. Compton, D.R.; Aceto, M.D.; Lowe, J.; Martin, B.R. In vivo characterization of a specific cannabinoid receptor antagonist (SR141716A): Inhibition of delta 9-tetrahydrocannabinol-induced responses and apparent agonist activity. J. Pharmacol. Exp. Ther. 1996, 277, 586-594. 
172. Jones, N.A.; Hill, A.J.; Smith, I.; Bevan, S.A.; Williams, C.M.; Whalley, B.J.; Stephens, G.J. Cannabidiol displays antiepileptiform and antiseizure properties in vitro and in vivo. J. Pharmacol. Exp. Ther. 2010, 332, 569-577.

173. Hill, A.J.; Weston, S.E.; Jones, N.A.; Smith, I.; Bevan, S.A.; Williamson, E.M.; Stephens, G.J.; Williams, C.M.; Whalley, B.J. $\Delta 9$-Tetrahydrocannabivarin suppresses in vitro epileptiform and in vivo seizure activity in adult rats. Epilepsia 2010, 51, 1522-1532.

174. Hill, A.J.; Mercier, M.S.; Hill, T.D.; Glyn, S.E.; Jones, N.A.; Yamasaki, Y.; Futamura, T.; Duncan, M.; Stott, C.G.; Stephens, G.J.; et al. Cannabidivarin is anticonvulsant in mouse and rat. Br. J. Pharmacol. 2012, 167, 1629-1642.

175. Ryan, D.; Drysdale, A.J.; Lafourcade, C.; Pertwee, R.G.; Platt, B. Cannabidiol targets mitochondria to regulate intracellular Ca2+ levels. J. Neurosci. 2009, 29, 2053-2063.

176. Scutt, A.; Williamson, E.M. Cannabinoids stimulate fibroblastic colony formation by bone marrow cells indirectly via CB2 receptors. Calcif. Tissue Int. 2007, 80, 50-59.

177. De Petrocellis, L.; Ligresti, A.; Moriello, A.S.; Allara, M.; Bisogno, T.; Petrosino, S.; Stott, C.G.; di Marzo, V. Effects of cannabinoids and cannabinoid-enriched Cannabis extracts on TRP channels and endocannabinoid metabolic enzymes. Br. J. Pharmacol. 2011, 163, 1479-1494.

178. Bisogno, T.; Howell, F.; Williams, G.; Minassi, A.; Cascio, M.G.; Ligresti, A.; Matias, I.; Schiano-Moriello, A.; Paul, P.; Williams, E.J.; et al. Cloning of the first sn1-DAG lipases points to the spatial and temporal regulation of endocannabinoid signaling in the brain. J. Cell. Biol. 2003, 163, 463-468.

179. Pertwee, R.G. Receptors and channels targeted by synthetic cannabinoid receptor agonists and antagonists. Curr. Med. Chem. 2010, 17, 1360-1381.

180. Dennis, I.; Whalley, B.J.; Stephens, G.J. Effects of Delta9-tetrahydrocannabivarin on [35S]GTPgammaS binding in mouse brain cerebellum and piriform cortex membranes. Br. J. Pharmacol. 2008, 154, 1349-1358.

181. Ma, Y.L.; Weston, S.E.; Whalley, B.J.; Stephens, G.J. The phytocannabinoid $\Delta^{9}$-tetrahydrocannabivarin modulates inhibitory neurotransmission in the cerebellum. $\mathrm{Br} . \mathrm{J}$. Pharmacol. 2008, 154, 204-215.

182. Campos, A.C.; Guimaraes, F.S. Involvement of 5HT1A receptors in the anxiolytic-like effects of cannabidiol injected into the dorsolateral periaqueductal gray of rats. Psychopharmacology 2008, 199, 223-230.

183. Russo, E.B.; Guy, G.W.; Robson, P.J. Cannabis, pain, and sleep: Lessons from therapeutic clinical trials of Sativex, a cannabis-based medicine. Chem. Biodivers. 2007, 4, 1729-1743.

184. Rahn, E.J.; Hohmann, A.G. Cannabinoids as pharmacotherapies for neuropathic pain: From the bench to the bedside. Neurotherapeutics 2009, 6, 713-737.

185. Borsook, D. Neurological diseases and pain. Brain 2012, 135, 320-344.

186. Koltzenburg, M.; Scadding, J. Neuropathic pain. Curr. Opin. Neurol. 2001, 14, 641-647.

187. Galuppo, M.; Giacoppo, S.; Bramanti, P.; Mazzon, E. Use of natural compounds in the management of diabetic peripheral neuropathy. Molecules 2014, 19, 2877-2895.

188. Costa, B.; Trovato, A.E.; Comelli, F.; Giagnoni, G.; Colleoni, M. The non-psychoactive cannabis constituent cannabidiol is an orally effective therapeutic agent in rat chronic inflammatory and neuropathic pain. Eur. J. Pharmacol. 2007, 556, 75-83. 
189. Calignano, A.; la Rana, G.; Giuffrida, A.; Piomelli, D. Control of pain initiation by endogenous cannabinoids. Nature 1998, 394, 277-281.

190. Farquhar-Smith, W.P.; Egertova, M.; Bradbury, E.J.; McMahon, S.B.; Rice, A.S.; Elphick, M.R. Cannabinoid CB(1) receptor expression in rat spinal cord. Mol. Cell. Neurosci. 2000, 15, 510-521.

(C) 2014 by the authors; licensee MDPI, Basel, Switzerland. This article is an open access article distributed under the terms and conditions of the Creative Commons Attribution license (http://creativecommons.org/licenses/by/4.0/). 